\title{
The 2013 severe haze over southern Hebei, China: model evaluation, source apportionment, and policy implications
}

\author{
L. T. Wang ${ }^{1,2,3}$, Z. Wei ${ }^{1,2}$, J. Yang ${ }^{1,2}$, Y. Zhang ${ }^{3}$, F. F. Zhang ${ }^{1,2}$, J. Su ${ }^{1,2}$, C. C. Meng ${ }^{1,2}$, and Q. Zhang ${ }^{4}$ \\ ${ }^{1}$ Department of Environmental Engineering, Hebei University of Engineering, Handan, Hebei 056038, China \\ ${ }^{2}$ State Environmental Protection Key Laboratory of Sources and Control of Air Pollution Complex, Beijing 100084, China \\ ${ }^{3}$ Department of Marine, Earth and Atmospheric Science, North Carolina State University, Raleigh, NC 27695, USA \\ ${ }^{4}$ Center for Earth System Science, Tsinghua University, Beijing 100084, China
}

Correspondence to: L. T. Wang (wanglitao@hebeu.edu.cn)

Received: 24 September 2013 - Published in Atmos. Chem. Phys. Discuss.: 1 November 2013

Revised: 13 January 2014 - Accepted: 20 February 2014 - Published: 31 March 2014

\begin{abstract}
Extremely severe and persistent haze occurred in January 2013 over eastern and northern China. The record-breaking high concentrations of fine particulate matter $\left(\mathrm{PM}_{2.5}\right)$ of more than $700 \mu \mathrm{g} \mathrm{m}^{-3}$ on hourly average and the persistence of the episodes have raised widespread, considerable public concerns. During that period, 7 of the top 10 polluted cities in China were within the Hebei Province. The three cities in southern Hebei (Shijiazhuang, Xingtai, and Handan) have been listed as the top three polluted cities according to the statistics for the first half of the year 2013. In this study, the Mesoscale Modeling System Generation 5 (MM5) and the Models-3/Community Multiscale Air Quality (CMAQ) modeling system are applied to simulate the 2013 severe winter regional hazes in East Asia and northern China at horizontal grid resolutions of 36 and $12 \mathrm{~km}$, respectively, using the Multi-resolution Emission Inventory for China (MEIC). The source contributions of major source regions and sectors to $\mathrm{PM}_{2.5}$ concentrations in the three most polluted cities in southern Hebei are quantified by aiming at the understanding of the sources of the severe haze pollution in this region, and the results are compared with December 2007, the haziest month in the period 2001-2010. Model evaluation against meteorological and air quality observations indicates an overall acceptable performance and the model tends to underpredict $\mathrm{PM}_{2.5}$ and coarse particulate matter $\left(\mathrm{PM}_{10}\right)$ concentrations during the extremely polluted episodes. The MEIC inventory is proven to be a good estimation in terms of total emissions of cities but uncertainties exist in the spatial allocations of emissions into fine grid resolutions within cities. The source apportionment shows
\end{abstract}

that emissions from northern Hebei and the Beijing-Tianjin city cluster are two major regional contributors to the pollution in January 2013 in Shijiazhuang, compared with those from Shanxi and northern Hebei for December 2007. For Xingtai and Handan, the emissions from northern Hebei and Henan are important. The industrial and domestic sources are the most significant local contributors, and the domestic and agricultural emissions from Shandong and Henan are non-negligible regional sources, especially for Xingtai and Handan. Even in the top two haziest months (i.e., January 2013 and December 2007), a large fraction of $\mathrm{PM}_{2.5}$ in the three cities may originate from quite different regional sources. These results indicate the importance of establishing a regional joint framework of policymaking and action system to effectively mitigate air pollution in this area, not only over the Beijing-Tianjin-Hebei area, but also surrounding provinces such as Henan, Shandong, and Shanxi.

\section{Introduction}

In February 2012, the Ministry of Environmental Protection (MEP) of China enacted the new National Ambient Air Quality Standards (CNAAQS), which are required to be enforced in many major cities and regions step by step before the nationwide enforcement becomes effective on 1 January 2016 (MEP, 2012). It sets the limits for the first time on fine particulate matter $\left(\mathrm{PM}_{2.5}\right)$, of $75 \mu \mathrm{g} \mathrm{m}^{-3}$ and $35 \mu \mathrm{g} \mathrm{m}^{-3}$ for daily and annual average concentrations, respectively. The limits for coarse particulate matter $\left(\mathrm{PM}_{10}\right)$ remain as $150 \mu \mathrm{g} \mathrm{m}^{-3}$ 
for daily average but lower for annual average from a previous $100 \mu \mathrm{g} \mathrm{m}^{-3}$ to $70 \mu \mathrm{g} \mathrm{m}^{-3}$ (SEPA, 1996). However, it is reported that only $\sim 30 \%$ of days on average in the 113 state key environmental protection cities can reach the new standards (MEP, 2013).

In January 2013, extremely severe, persistent haze occurred in eastern and central China, raising considerable public attention. This month has been reported as the haziest month in the past 60 years in Beijing (Lu et al., 2013). The daily concentrations of $\mathrm{PM}_{2.5}$ at some sites in Beijing and Shijiazhuang (the capital city of Hebei Province) have been over $500 \mu \mathrm{g} \mathrm{m}^{-3}$, which is 6.7 times the new CNAAQS. The corresponding air quality index (AQI) cannot even be calculated because the observed $\mathrm{PM}_{2.5}$ concentrations exceeded the upper limit value defined in the calculation of AQI. Since then, the China National Environmental Monitoring Center (CNEMC) has published the 10 most polluted and clearest cities in China every month. The top 10 polluted cities in January 2013 included Xingtai, Shijiazhuang, Baoding, Handan, Langfang, Hengshui, Jinan, Tangshan, Beijing, and Zhengzhou. Seven out of the 10 cities are located in Hebei. The three cities in southern Hebei, i.e., Xingtai, Shijiazhuang, and Handan, are listed in the top four polluted cities by CNEMC in January 2013 and the top three in the most recent report of CNEMC on the assessment of urban air quality for January to June 2013 (http://www.cnemc.cn/publish/106/ news/news_37027.html). Air pollution in Hebei has raised widespread public concerns in China and worldwide.

Hebei Province, located in northern China, has an area of $187700 \mathrm{~km}^{2}$ and population of 71.85 million. It extends west to the Taihang Mountains and south to the Yellow River, and encloses two megacities, Beijing and Tianjin. Most of the northwest area of Hebei is mountainous or hilly, and the central and south areas belong to the North China Plain (NCP). Hebei has a monsoon climate of medium latitudes, which has dry and windy springs, hot and rainy summers, and dry and cold winters (L. T. Wang et al., 2013). The prevailing winds are northwest in winter and southeast in summer. Hebei's gross domestic product (GDP) in 2011 was 2.45 trillion RMB, ranked 6th in China (NBS, 2012a). The major industrial manufacturers in Hebei include coal, power, steel and iron, ceramics, petroleum, and pharmaceutics. According to the Natural Bureau of Statistics (NBS), $24.0 \%$ of steel, $14.5 \%$ of coke and $6.9 \%$ of cement in China were produced in Hebei in 2011 (NBS, 2012a, b). Most of these industrial manufacturers emit large amounts of air pollutants. The emissions of primary $\mathrm{PM}_{2.5}, \mathrm{PM}_{10}$, sulfur dioxide $\left(\mathrm{SO}_{2}\right)$, and nitrogen oxides $\left(\mathrm{NO}_{\mathrm{x}}\right)$ from Hebei are estimated to be as high as $7.4 \%, 7.5 \%, 7.4 \%$, and $6.3 \%$, respectively, in the national total emissions in China, according to the widely used Intercontinental Chemical Transport Experiment (INTEX-B) emission inventory (Zhang et al., 2009). Very dense emission sources within Hebei is one of the causes for the severe air pollution occurring in Hebei.
The special location of the three southern Hebei cities, Shijiazhuang, Xingtai, and Handan, should be taken into account when analyzing the reasons for the extremely heavy pollution. They are located in the intersectional area of four provinces Hebei, Shandong, Henan and Shanxi. All of them are heavily populated, industrialized, and urbanized. The northwest prevailing wind in winter can bring pollutants from northern Hebei, Beijing, Tianjin, and Shanxi, and the southeast wind in summer may transport pollutants from Shandong and Henan. Shandong and Henan's GDP ranked 3rd and 5th, respectively, in China in 2011 (NBS, 2012a). Shandong is the biggest agricultural province and Shanxi is a leading coal producer in China. The four provinces together produced $50.1 \%$ of coke, $40.8 \%$ of steel, and $22.6 \%$ of cement in China in 2011 (NBS, 2012a, b). Note that China's national productions of coke, steel, and cement were about $60 \%, 45.5 \%$, and $60 \%$ of the world, respectively (NBS, 2012a). The four provinces thus produce about $30 \%$ of coke, $18.6 \%$ of steel, and $13.6 \%$ of cement in the world. In the INTEX-B emission inventory, the total emissions from these four provinces account for $28.7 \%, 27.9 \%, 28.3 \%$, and $25.0 \%$ in the national emissions of $\mathrm{PM}_{2.5}, \mathrm{PM}_{10}, \mathrm{SO}_{2}$, and $\mathrm{NO}_{\mathrm{x}}$, respectively (Zhang et al., 2009). These industrial manufacturers create a heavy burden on air quality in the four provinces and surrounding areas.

The Community Multiscale Air Quality Model (CMAQ) system has been increasingly applied in the past few years to simulate air quality in China, in particular, under various emission reduction scenarios in support of the development of the emission control measures for the 2008 Beijing Olympics (e.g., Streets et al., 2007; Chen et al., 2007, 2008; L. T. Wang et al., 2008, 2010; K. Wang et al., 2009; Fu et al., 2009; Zhou et al., 2010; S. X. Wang et al., 2011; Xing et al., 2011; Zhou et al., 2012; Gao and Zhang, 2012; Li et al., 2013). CMAQ has been evaluated and proven to be a creditable tool by several studies in Asia (e.g., M. Zhang et al., 2006; Uno et al., 2007; Fu et al., 2008; L. T. Wang et al., 2008, 2010, K. Wang et al., 2009; and Liu et al., 2010a, b). These studies, however, focused largely on either all of China or the three major polluted regions in China, NCP, the Yangtze River Delta (YRD), and the Pearl River Delta (PRD). In addition, among all 3-D regional air quality model applications in China, very few studies provide a comprehensive examination of the contributions of major source regions and source sectors to particulate matter (PM) concentrations in major receptor cities such as Beijing, Tianjin, and those most polluted cities in southern Hebei. Most of the previous studies involving Hebei aimed at the air quality improvement in Beijing and Tianjin, especially for the 2008 Beijing Olympics (Streets et al., 2007; Chen et al., 2007, 2008; L. T. Wang et al., 2008; Fu et al., 2009; Xing et al., 2011; Gao and Zhang, 2012). By performing CMAQ simulations with and without emissions from Hebei Province, these studies concluded that $20-40 \%$ of air polluants in Beijing came from Hebei Province. There are only a few studies on air 
quality in Hebei. Most focused on the long-term statistical analyses of haze frequencies (Fan et al., 2005; Wei, 2010), and their statistical relationships with meteorological factors (Wei et al., 2010) and the concentrations of $\mathrm{PM}_{10}$ (Zhang, 2009). Only one study used a 3-D air quality model to understand the formation mechanisms and sources of the severe haze pollution in Hebei (L. T. Wang et al., 2012). In L. T. Wang et al. (2012), the Mesoscale Modeling System Generation 5 (MM5) and CMAQ were applied to simulate air quality in southern Hebei in December 2007, the most polluted month during the period 2001-2010, and quantify the contributions of source regions to the $\mathrm{PM}_{2.5}$ concentrations in Shijiazhuang and Xingtai. They found that haze pollution over southern Hebei was a regional problem, and the transboundary pollution played an important role during the haze period.

In this paper, the work of L. T. Wang et al. (2012) is extended in several aspects. First, haze frequencies in the seven representative cities in northern China are analyzed for the period January 2001 to February 2013, whereby January 2013 is found to be the most polluted month since 2001. Second, the regional haze events in January and February 2013 are simulated using the MM5-CMAQ system; the model predictions are evaluated against meteorological and real-time air quality observations in China. Third, the source contributions of major source regions to the $\mathrm{PM}_{2.5}$ concentrations in the three most polluted cities, Shijiazhuang, Xingtai, and Handan during the two months are quantified and compared with the results for December 2007 of L. T. Wang et al. (2012). Finally, the contributions by each source sector in each source region are also analyzed to further identify the most influential contributors to the severe haze pollution in those three cities. The objectives of this study are to quantify the contributions of local and regional sources to the extremely severe haze pollution over the major cities in southern Hebei and provide scientific information for policymaking on the future air pollution control in this region at the province level and under a regional jointly controlled framework.

Compared to previous studies, this study has several distinct features. First, this work represents the most comprehensive 3-D air quality modeling study focusing on southern Hebei. Second, this work performs an extensive set of CMAQ simulations with the Brute Force method (BFM) (Dunker et al., 1996) during the most severe winter regional haze episodes to quantify source contributions from five major source sectors in six major source regions in northern China for three most polluted cities in southern Hebei, aiming at the understanding of major source contributors to the most severe air pollution episodes in this region. Third, the simulation of January and February 2013 is evaluated using the real-time observations of concentrations of $\mathrm{PM}_{2.5}$ and $\mathrm{PM}_{10}$ released by CNEMC since January 2013 at 496 individual monitoring stations in northern China. To our best knowledge, this work is the first study that directly uses such real-time hourly observational data from CNEMC for model evaluation in China. This data set allows the evaluation of the uncertainties in the spatial allocations of regional inventories, for the first time. Previous studies used the concentrations of $\mathrm{PM}_{10}, \mathrm{SO}_{2}$, and nitrogen dioxide $\left(\mathrm{NO}_{2}\right)$ derived based on average air pollution index (API) in major Chinese cities released by CNEMC. Such API-derived concentrations are not direct measurements but the average values of multiple representative sites within cities, and may contain some uncertainties.

The paper is organized as follows: Sect. 2 describes the modeling episode, configurations, and evaluation protocols. Section 3 presents the modeling results and their evaluation against the observations at the 496 monitoring sites in China. Section 4 examines the source contributions by six source regions and by five source sectors in each of the three receptor regions during January and February 2013 and compares them with the results of December 2007 in L. T. Wang et al. (2012). Section 5 summarizes major findings and limitations of this work.

\section{Methodology}

\subsection{Modeling domain and episode}

As shown in Fig. 1, MM5 and CMAQ simulations are performed over two nested domains: East Asia with a grid resolution of $36 \times 36 \mathrm{~km}$ (Domain 1) and an area in northeastern China encompassing Beijing, Tianjin, and the four provinces: Hebei, Henan, Shandong, and Shanxi at a $12 \times 12 \mathrm{~km}$ grid resolution (Domain 2). The three key cities in southern Hebei, i.e., Shijiazhuang, Xingtai, and Handan are located at the center of Domain 2. January and February 2013 are chosen as the modeling period. The regional haze events during this period, in particular, January 2013, represent the most severe episodes with the highest $\mathrm{PM}_{2.5}$ concentrations in China since 2001. A spin-up period of 5 days (27-31 December 2012 ) is used to minimize the influence of the initial conditions.

\subsection{Model configurations and inputs}

This work uses the same configurations as those of L. T. Wang et al. (2012) to ensure a consistency with the December 2007 MM5-CMAQ simulations. A brief description of model setup is provided below. More detailed descriptions can be found in L. T. Wang et al. (2012). MM5 model version 3.7 is used to generate meteorological fields for the CMAQ simulations. Overall, 23 sigma levels are used for the vertical grid structure from surface to tropopause $(\sim 100 \mathrm{mb})$. The data sources for MM5 simulation include: the US Geological Survey database (ftp://ftp.ucar.edu/mesouser/MM5V3/ TERRAIN_DATA/) for the terrain and land use data; the National Center for Environmental Prediction (NCEP) Final (FNL) Operational Global Analysis data sets for initial and 


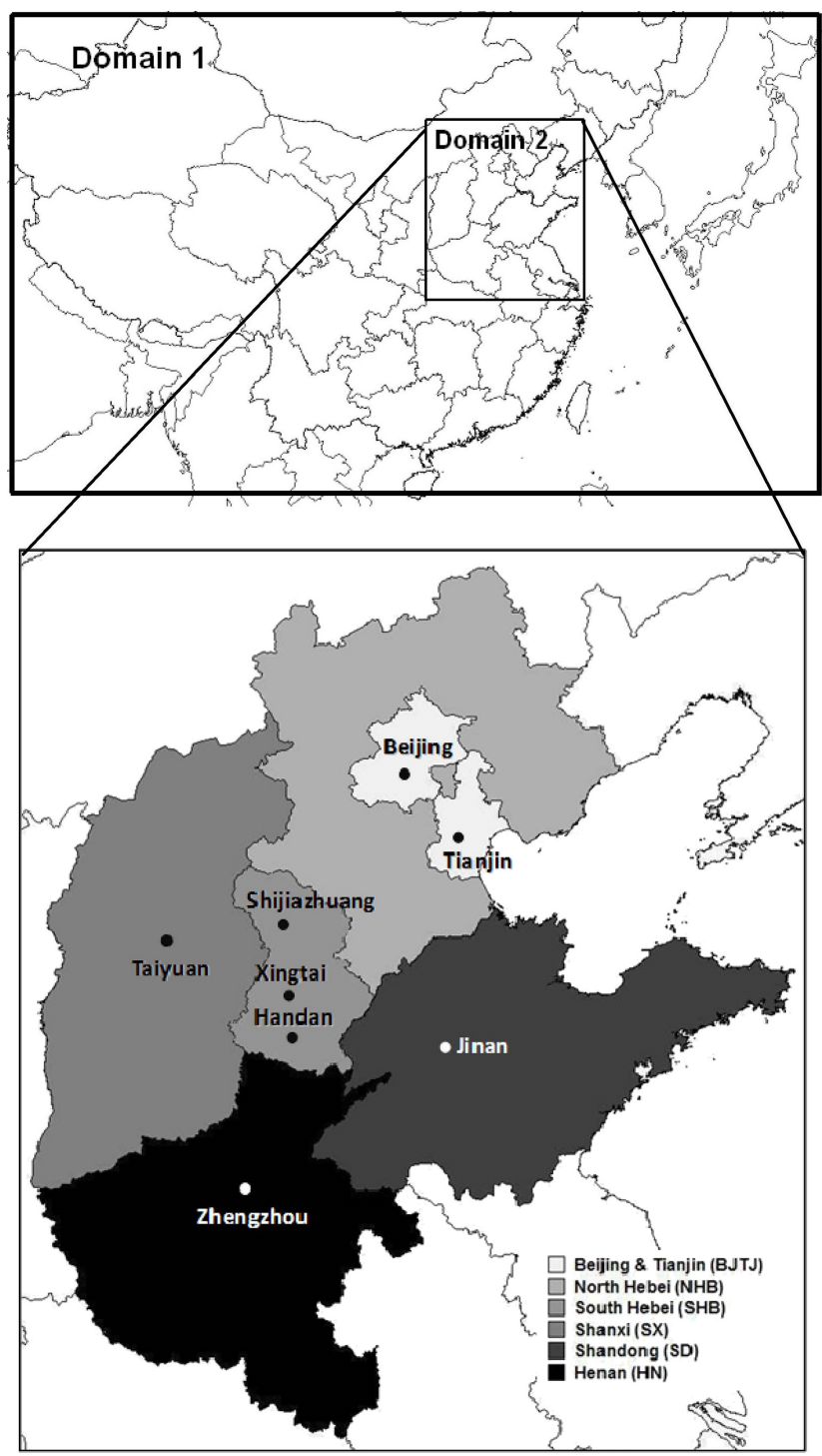

Fig. 1. CMAQ modeling domains at a horizontal grid resolution of $36 \mathrm{~km}$ over East Asia (Domain 1 with $164 \times 97$ cells) and $12 \mathrm{~km}$ over an area in northeastern China (Domain 2 with $93 \times 111$ cells). The zoom-in area (Domain 2) shows the regions focused in the analysis of source contributions. It includes six regions of interest: southern Hebei (which includes three cities: Shijiazhuang, Xingtai, and Handan), northern Hebei (which includes the remaining areas in the Hebei Province), Shanxi Province (SX), Shandong Province (SD), Henan Province (HN), and a two-city cluster region covering Beijing and Tianjin (BJTJ).

boundary meteorological conditions; the NCEP Automated Data Processing (ADP) surface and upper air data for the four-dimensional data assimilation (FDDA). The analysisnudged parameters include wind, temperature, and the water vapor mixing ratio both in and above planetary boundary layer (PBL).

Two-way nesting is used for the MM5 simulation. The major physics options are the same as those of L. T. Wang et al. (2012), including the Kain-Fritsch cumulus scheme (Kain and Fritsch, 1993), the high-resolution Blackadar PBL scheme (Zhang and Anthes, 1982), the mixed phase (Reisner 1) explicit moisture scheme (Reisner et al., 1998), the cloud atmospheric radiation scheme for both longwave and shortwave radiation (Dudhia, 1993), and the force/restore (Blackadar) surface scheme (Blackadar, 1976; Deardorff, 1978). The Meteorology-Chemistry Interface Processor (MCIP) version 3.6 is applied to process the meteorological data for CMAQ.

The CMAQ version 4.7.1 is used in this study. The vertical resolution includes 14 layers from the surface to the tropopause with the corresponding sigma levels of 1.000 , 0.995, 0.988, 0.980, 0.970, 0.956, 0.938, 0.893, 0.839, 0.777, $0.702,0.582,0.400,0.200$, and 0.000 . The gaseous and aerosol modules are the SAPRC-99 chemical mechanism (Carter, 1990, 2000) with aqueous and aerosol extensions, and the AERO5 model (Binkowski and Shankar, 1995), respectively. The aqueous-phase chemistry is based on the updated mechanism of the Regional Acid Deposition Model (RADM) model (Chang et al., 1987; Walcek and Taylor, 1986). Dust emissions are not included since CMAQ v4.7.1 does not include online dust emissions.

The initial chemical conditions (ICON) for Domain 1 use the default clean profile available in CMAQ. The chemical boundary conditions (BCON) used for Domain 1 are the default profile available in CMAQ, and those for Domain 2 are generated from Domain 1. To calculate the photolysis rate for CMAQ using the photolysis rates processor (JPROC), the total ozone column data are obtained from the Ozone Measurement Instrument (OMI) (http://toms.gsfc.nasa.gov/ ozone/ozone_v8.html) on the Aura satellite.

Emissions are extremely important to the accuracy of air quality modeling results. The Multi-resolution Emission Inventory for China (MEIC) (He, 2012) for the base year 2010 is used in this study. The MEIC inventory uses a dynamic, technology-based methodology for all the anthropogenic emissions of eight species, including $\mathrm{SO}_{2}, \mathrm{NO}_{\mathrm{x}}$, carbon monoxide (CO), non-methane volatile organic compounds (NMVOCs), ammonia $\left(\mathrm{NH}_{3}\right)$, carbon dioxide $\left(\mathrm{CO}_{2}\right)$, $\mathrm{PM}_{10}$, and $\mathrm{PM}_{2.5}$ in China for the years 1990 to 2010. MEIC was developed by the same group at Tsinghua University, China by continuously updating and improving the emission databases (Zhang et al., 2007, 2009; Lei et al., 2011a). Compared with the previous inventories (e.g., Transport and Chemical Evolution over the Pacific (TRACE-P) inventory, or INTEX-B), the major improvements of MEIC include unit-based emission inventory for power plants (S. W. Wang et al., 2012) and cement plants (Lei et al., 2011b) and an online emission process database (http://www.meicmodel.org). It should be noted that for the simulation of the period January to February 2013 in this work, the total emissions may be underestimated, because of the economic increase during the period 2010-2013. The national GDP increased 9.3\% and $7.8 \%$ in 2011 and 2012, respectively (NBS, 2013). 


\subsection{Emission reduction scenarios and simulation design}

In addition to the baseline simulation, CMAQ with the Brute Force method (BFM) (Dunker et al., 1996) is used to evaluate the source contributions to concentrations from specific source regions and sectors of interest. Namely, the contributions of a region or a sector are estimated by calculating the differences between the baseline simulation and the sensitivity simulation in which the anthropogenic emissions of that region or sector are set as zero (referred to as zero-out BFM). Strictly speaking, the BFM is a source sensitivity (SS) method (Burr and Zhang, 2011a, b), and it will not provide source apportionment (i.e., the sum of all source contributions equals the simulated baseline concentrations) if the relationship between the model input and output is non-linear, which is the case for 3-D PM modeling. Nevertheless, the zero-out BFM has been applied extensively in the past and is an effective way to approximate the contributions of various sources to support the policymaking in air pollution controls in major source regions in China (Streets et al., 2007; Chen et al., 2007; L. T. Wang et al., 2008; Fu et al., 2009; Zhou et al., 2010; Xing et al., 2011) and other regions in the world (e.g., Marmur et al., 2005; Burr and Zhang, 2011a; Zhang and Wu, 2013).

Although BFM with multiple scenarios is computationally expensive, following L. T. Wang et al. (2012), it is selected for source apportionment in this work because it is straightforward and can simulate the non-linear relationship among PM and PM precursors and indirect effects resulting from interactions between secondary PM species and non-direct gaseous precursors for large emission changes. It should be mentioned that another source sensitivity method using CMAQ is the embedded tool of Decoupled Direct Method in 3 Dimensions (DDM-3D) developed in recent years (Yang et al., 1997; Dunker et al., 2002; Cohan et al., 2005; Napelenok et al., 2006). It directly calculates the sensitivities of multiple sources and parameters at the same time of the baseline simulation, thus effectively reducing the computing time. However, DDM implemented in CMAQ only calculates the local first-order sensitivities for aerosols species, which cannot accurately predict the changes of chemical concentrations under large emission perturbations (i.e., larger than 40\%) (Zhang et al., 2005). A different approach for source apportionment is the tagged species method, i.e., some tracer species from specific source categories are added in the 3-D models, which undergo the same processes as the bulk species to track the contributions from those sources during the model simulation. The Tagged Species Source Apportionment algorithm (TSSA) (Tonnessen et al., 2007; Z. S. Wang et al., 2009) and the Particulate Precursor Tagging Methodology (PPTM) (US EPA, 2009) within CMAQ are two of those tools. They can attribute $100 \%$ of concentration to emission sources but their main weakness lies in the omission of the indirect effects because of several assumptions for the secondary PM calculation, e.g., all secondary
$\mathrm{PM}$ is linked to a specific precursor (sulfate to $\mathrm{SO}_{\mathrm{x}}$, nitrate to $\mathrm{NO}_{\mathrm{x}}$, and ammonium to $\mathrm{NH}_{3}$ ), so that an increase in nitrate concentrations due to a reduction in $\mathrm{SO}_{2}$ emissions cannot be reflected. In addition, CMAQ with TSSA or PPTM are not available for public use in the recent CMAQ versions including CMAQ v4.7.1.

Following L. T. Wang et al. (2012), six source regions in Domain 2 are selected in the regional contribution analysis (see Fig. 1). They include southern Hebei (SHB), northern Hebei (NHB), Shanxi province (SX), Shandong province (SD), Henan province (HN), and a two-city cluster region covering Beijing and Tianjin (BJTJ). Five major emission sectors are considered in sector contribution analysis including power plants (PO), industrial (IN), domestic (DO), transportation (TR), and agriculture (AG). Those five sectors cover about $93 \%$ to $98 \%$ of total emissions of $\mathrm{PM}_{2.5}$, $\mathrm{PM}_{10}, \mathrm{SO}_{2}$ and $\mathrm{NO}_{\mathrm{x}}$ in the six regions of interest in winter. Only two sectors, biomass open burning and biogenic emissions, are not included, because although the open burning of crop residues is an anthropogenic and controllable emission in biomass open burning, it usually occurs in summer and autumn and is not considered as one of the major sources in this study. The biogenic emissions are not anthropogenic in nature and are considered to be uncontrollable in this study, although recent studies have quantified a controllable fraction of secondary organic aerosol resulted from biogenic volatile organic compounds in the southeastern US (Carlton et al., 2010) and East Asia (Glotfelty et al., 2013). For each of the six source regions, the emissions from each of the five major sectors are zeroed out individually (referred to as simulations PO, IN, DO, TR, and AG, respectively) and collectively (referred to as AL). The analysis of source sensitivities focuses on the three major receptor cities in southern Hebei, in other words, Shijiazhuang, Xingtai, and Handan, which are the most polluted cities in both this region and China during the most severe regional haze in January 2013. In addition, the source contributions of those three cities to each other are assessed, by zeroing out the emissions in each of the three cities, in order to understand their mutual influences. Therefore, a total of forty 2-month simulations, including 39 emission zero-out scenarios $(=6$ source regions $\times(5$ sectors +1 $\mathrm{AL})+3$ ) plus one baseline, are performed in this study.

\subsection{Model evaluation data set and protocols}

Table 1 summarizes the observational data used for model evaluation in this study. The meteorological data used in this study are obtained from the National Climate Data Center (NCDC) integrated surface database and the evaluations are performed for the five major parameters that affect air pollution: temperature at $2 \mathrm{~m}(\mathrm{~T} 2)$, relative humidity at $2 \mathrm{~m}$ (RH2), wind speed at $10 \mathrm{~m}$ (WS10), wind direction at $10 \mathrm{~m}$ (WD10), and daily precipitation. For January to February, data every 1 or $3 \mathrm{~h}$ (most at $3 \mathrm{~h}$ ) at a total of 371 sites within our domains are available. 
Table 1. Observational data sets for model evaluation used in this study.

\begin{tabular}{|c|c|c|c|c|c|c|}
\hline Data set ${ }^{\mathrm{a}}$ & Data type & Variable $^{\mathrm{b}}$ & Data frequency & Site number & Time period & Data sources \\
\hline NCDC & Meteorology & $\begin{array}{l}\text { T2, RH2, WD10, WS10, } \\
\text { Precipitation }\end{array}$ & $\begin{array}{l}\text { Every } 1 \text { or } 3 \mathrm{~h} \\
\text { Daily }\end{array}$ & 371 & 1 Jan-28 Feb 2013 & http://www.ncdc.noaa.gov/data-access/quick-links\#ghen \\
\hline CNEMC & Air quality & $\mathrm{PM}_{2.5}, \mathrm{PM}_{10}$ & Hourly & 496 & 13 Jan- 28 Feb 2013 & http://113.108.142.147:20035/emcpublish \\
\hline HEBEU & Air quality & $\mathrm{PM}_{2.5}, \mathrm{PM}_{10}$ & Hourly & 1 & 1 Jan-28 Feb 2013 & Wei et al. (2013) \\
\hline
\end{tabular}

The chemical concentrations evaluated in this study include $\mathrm{PM}_{2.5}$ and $\mathrm{PM}_{10}$ using observations from two data sets. The first one is the CNEMC's real-time database for pollutant concentrations. In L. T. Wang et al. (2012), the API data published daily by MEP were used to evaluate model performance following a number of past studies (Streets et al., 2007; Chen et al., 2007; Wang et al., 2008, 2010; Fu et al., 2009; Liu et al., 2010a; Xing et al., 2011). This database is the only public accessible air quality data until 2011 when the real-time hourly concentrations of $\mathrm{SO}_{2}, \mathrm{NO}_{2}$, and $\mathrm{PM}_{10}$ at all national sites in the key environmental protection cities started to be available on the web site of the CNEMC (http://58.68.130.147/air/). Since January 2013, the CNEMC began to release the real-time hourly concentrations of $\mathrm{SO}_{2}, \mathrm{NO}_{2}, \mathrm{CO}$, ozone $\left(\mathrm{O}_{3}\right), \mathrm{PM}_{2.5}$, and $\mathrm{PM}_{10}$ at 496 national monitoring stations in 74 major cities in China. The 74 cities include all the capital cities of each province, municipalities, and all the cities within the Beijing-Tianjin-Hebei area (BTH), the YRD, and the PRD (http://113.108.142.147: 20035/emcpublish/). Such real-time air quality data provide a much better database for model evaluation and are thus used in this work. However, the main difficulty in using this realtime database lies in the inaccessibility of the historic data of more than $24 \mathrm{~h}$ ago, as the data are no longer available on its web site after $24 \mathrm{~h}$ posting. For this reason, the data used in model evaluation are for the period 14 January-28 February, 2013, and those for 1-13 January 2013 are not available and thus not used in the model evaluation in this study. The second data source available to this study is the observations at a site located in the Hebei University of Engineering (refer to HEBEU) measured by the lead author's group since July 2012 (Wei et al., 2013). HEBEU is located in the southeast edge of the urban area of Handan, where the continuous $\mathrm{PM}_{2.5}$ and $\mathrm{PM}_{10}$ concentrations are measured. More detailed descriptions of the characteristics of the site and measurement method can be found in Wei et al. (2013). The observed hourly $\mathrm{PM}_{2.5}$ and $\mathrm{PM}_{10}$ concentrations at this site are used in the model evaluation for both January and February 2013.

The meteorological evaluation is performed in terms of domain-wide overall statistics. The statistical measures calculated include the mean bias (MB), the root mean square error (RMSE), the normalized mean bias (NMB), and the normalized mean error (NME), which are defined in Y. Zhang et al. (2006). The chemical evaluation is performed in terms of the overall statistics, spatial distribution, and temporal vari- ations at the representative cities, following the guidance by US Environmental Protection Agency (US EPA, 2007). In addition to NMB and NME, the mean fractional bias (MFB) and the mean fractional error (MFE) are analyzed and they are also defined in Y. Zhang et al. (2006). For both $36 \mathrm{~km}$ and $12 \mathrm{~km}$ domains, the observations of multiple sites are averaged, if they fall into the same grid, and are compared with the predictions extracted from that grid. For grid cells that only contain a single monitoring site, the observed value at this site is compared with the prediction in this grid cell.

\section{Haze episode analyses and model evaluation}

\subsection{Haze frequencies and visibilities in the representative cities}

In L. T. Wang et al. (2012), haze frequencies in the seven representative cities in northern China, Shijiazhuang, Xingtai, Beijing, Tianjin, Taiyuan, Zhengzhou, and Jinan (see Fig. 1), were examined for the period 2001 to 2010, and December 2007 was found to be the haziest month during the 10 years. The hazy days from 2011 to February 2013 are further identified in this study, according to the meteorological observations in those cities using the same criteria as those used in L. T. Wang et al. (2012). Figure 2 summarizes the average monthly hazy days that occurred in the seven cities since 2001. Haze weather was much more frequent in winter, especially in January and December. December 2007 and January 2013 were the top polluted months since 2001 each with an average of 14 hazy days, followed by January 2006 (an average of 13 days), January 2012 (12.6 days), December 2011 (12 days), and February 2013 (11.6 days). January and February 2013, as the top first and sixth haziest months, respectively, since 2001, are representative periods to evaluate the sources of air pollution during the very severe pollution episode.

The number of hazy and foggy days that occurred in the seven cities in the 3 representative months, December 2007, and January and February 2013, are summarized along with the average monthly visibilities in Fig. 3. The foggy days are determined when it was recorded as "foggy weather" according to the WMO (Weather Meteorological Organization) meteorological code or when the relative humidity was above $90 \%$ and the visibility was less than $10 \mathrm{~km}$ but there was no any other types of weather that influenced the visibility such 


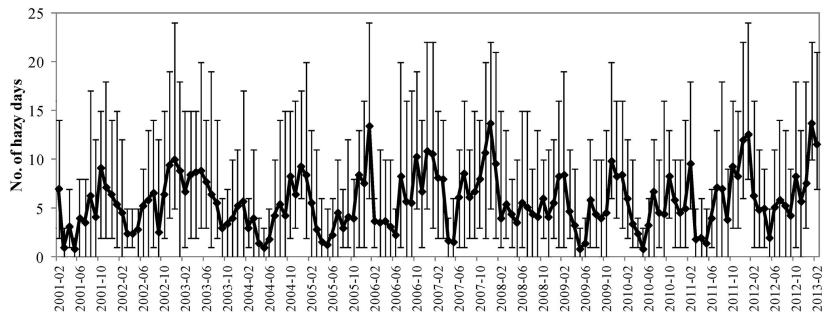

Fig. 2. The monthly average number of hazy days that occurred in the seven representative cities in Domain 2, including Shijiazhuang, Xingtai, Beijing, Tianjin, Taiyuan, Zhengzhou, and Jinan, during January 2001 to February 2013. The lines indicate the minimum and maximum number of hazy days in the seven cities.

as precipitation and sandstorm. Although January 2013 and December 2007 have the same total number of hazy days, several cities such as Shijiazhuang, Xingtai, and Zhengzhou had more frequent fog days in January 2013 than in December 2007 ( 8 vs. 1,5 vs. 2 , and 2 vs. 0 , respectively). The total number of the foggy days in the seven cities is as high as 21 in January 2013, compared with 14 in December 2007 and only 3 in February 2013. Foggy weather not only indicates a very stable atmosphere that can facilitate accumulation of the pollutants, but also results in a growth of atmospheric aerosol particles due to water uptake. Persistently hazy/foggy weather will further reduce the incoming solar radiations that in turn result in a more stable atmosphere and an increased pollutant accumulation. February 2013 was much dryer than the other 2 months with only 1 foggy day occurring in Xingtai, Beijing, and Jinan.

As shown in Fig. 3a, January 2013 was the top polluted month in terms of the total frequencies of hazy/foggy weather among the 3 representative months in most of the seven cities, except for Xingtai and Taiyuan. For example, the number of hazy/foggy days in Tianjin is 17 in January 2013, which is much higher than 10 days in December 2007, and 9 days in February 2013. Zhengzhou, Shijiazhuang, Xingtai, and Tianjin were the most polluted cities in terms of their total numbers of hazy and foggy days, which were 24, 22, 17, and 17 , respectively.

The monthly average visibilities of the seven key cities are calculated according to the meteorological observations at the 06:00 GMT (corresponding to 14:00 in Beijing local standard time) every day to avoid the influence of the radiation fog appeared in the morning, as discussed in L. T. Wang et al. (2012). As shown in Fig. 3b, the lowest visibility in terms of the monthly seven-city average was only $8.5 \mathrm{~km}$, which occurred in January 2013. This number is $13.7 \%$ lower than that in December $2007(9.8 \mathrm{~km})$ and $21.9 \%$ lower than that in February $2013(10.8 \mathrm{~km})$. In terms of the haze/fog frequencies and the visibilities, air pollution in January 2013 is much more severe than those in the other 2 months, and those in February 2013 are the best among the 3 months analyzed.

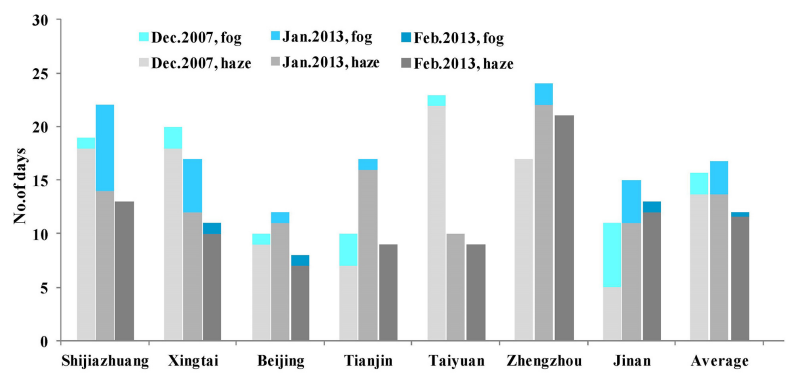

(a)

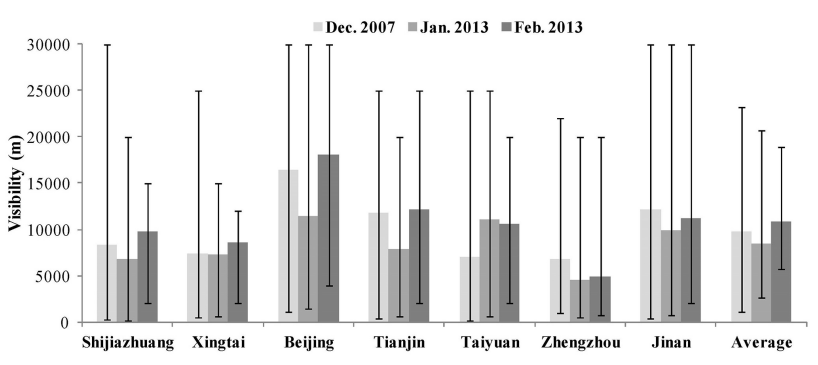

(b)

Fig. 3. The monthly total number of (a) hazy and foggy days and (b) the average visibilities in the seven representative cities in northern China in December 2007, and January and February 2013. The line in (b) indicates the minimum and maximum daily visibilities.

\subsection{Model performance evaluation}

\subsubsection{Meteorological predictions}

Table 2 shows the performance statistics for the meteorological predictions over Domain 1 at the $36 \mathrm{~km}$ resolution and Domain 2 at both 36 and $12 \mathrm{~km}$ resolutions. The nearsurface temperature is overall underpredicted in both domains. The MBs for the $36 \mathrm{~km}$ domain are $-1.5^{\circ} \mathrm{C}$ for both January and February. Predictions over Domain 2 at $12 \mathrm{~km}$ resolution in terms of MBs agree better with the observations than those at $36 \mathrm{~km}$, with MBs of $-1.1{ }^{\circ} \mathrm{C}$ and $-0.9^{\circ} \mathrm{C}$ for January and February, comparing to $\mathrm{MBs}$ of $-1.2^{\circ} \mathrm{C}$ and $-1.0^{\circ} \mathrm{C}$, respectively, at $36 \mathrm{~km}$. The large cold biases in $\mathrm{T} 2$ mainly occur in western China, especially over the Tibetan Plateau during both months, which were covered by thick snow layers. Such large cold biases reflect the limitations of MM5 in treatments of snow-related processes and snow effects (Zhang et al., 2011; Liu et al., 2010c). Relative humidity at $2 \mathrm{~m}$ agrees well with the observations with MBs ranging from $-0.5 \%$ to $-8.0 \%$ and NMBs ranging from $-0.8 \%$ to $-12.6 \%$ for both domains. It is slightly underpredicted, especially in Domain 2. Wind speed at $10 \mathrm{~m}$ is well reproduced in both domains, with MBs and NMBs ranging from 0.6 to $0.8 \mathrm{~m} \mathrm{~s}^{-1}$, and $23.2 \%$ to $33.8 \%$, respectively. For wind direction at $10 \mathrm{~m}$, MBs for Domain 1 are $-10.0^{\circ}$ for January 


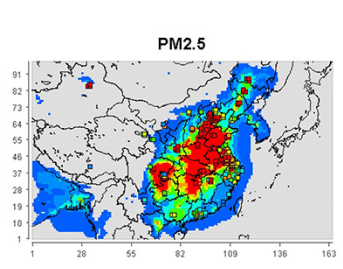

January
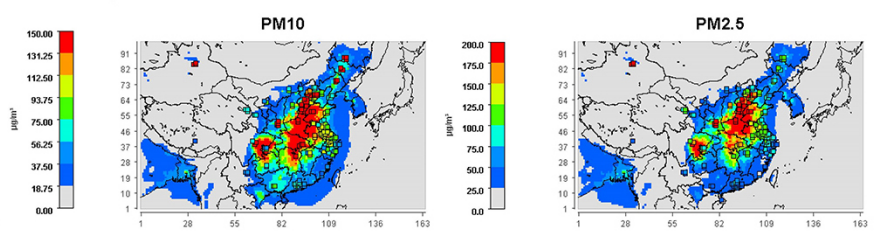

February

(a)
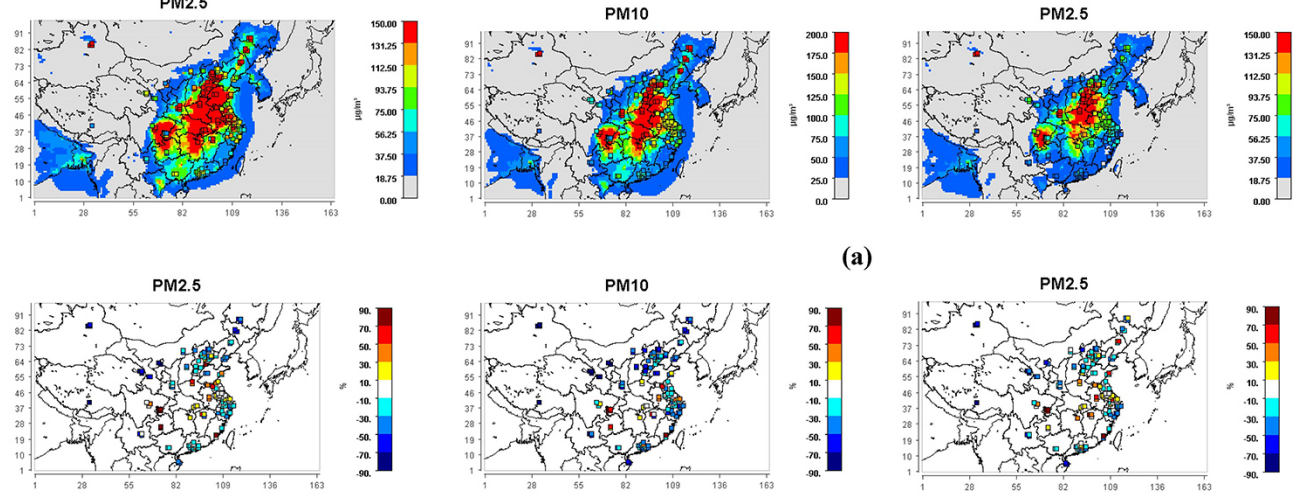
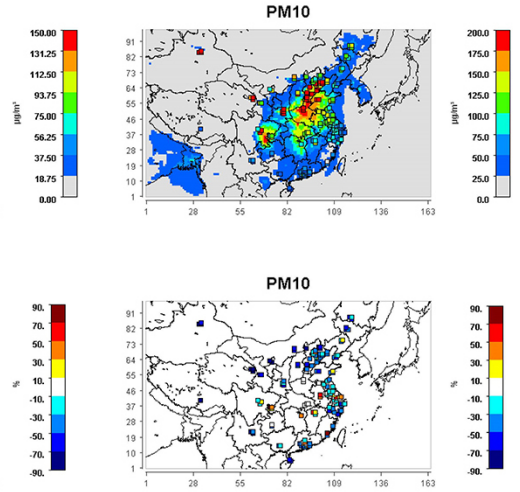

(b)

Fig. 4. (a) Overlay of the simulated and observed monthly average concentrations of $\mathrm{PM}_{2.5}$ and $\mathrm{PM}_{10}$ of the reported 74 cities and (b) the corresponding spatial distributions of $\mathrm{NMBs}$ for $\mathrm{PM}_{2.5}$ and $\mathrm{PM}_{10}$ at $36 \mathrm{~km}$ horizontal grid resolution for January and February, 2013. Note the average for January is calculated from 14 January to 31 January due to the lack of data in 1-13 January. Square signs indicate the observations.

and $-12.9^{\circ}$ for February, and $7.1^{\circ}$ and $-2.7^{\circ}$ for Domain 2 at $36 \mathrm{~km}$ resolution and $0.1^{\circ}$ and $-8.1^{\circ}$, respectively, at $12 \mathrm{~km}$. It should be noted that the differences between the predictions and observations for wind direction may not reflect the real differences because it is a vector; e.g., the actual difference between $0^{\circ}$ and $360^{\circ}$ are zero instead of the calculated numeric difference of $360^{\circ}$ (Y. Zhang et al., 2006). Precipitation is underpredicted for both months, with NMBs of $-31.6 \%$ and $-7.2 \%$ for January and February for Domain 1 , and $-43.9 \%$ and $-34.7 \%$ for Domain 2 at $36 \mathrm{~km}$, and $-44.2 \%$ and $-36.7 \%$ at $12 \mathrm{~km}$, respectively. The results at a fine grid resolution do not give a better performance. The likely reasons for moderate-to-large underpredictions in precipitation include the limitations in the model treatments, such as the cloud microphysics module used or inaccuracies in the model inputs, such as land use data over complex terrains, as discussed in several studies (e.g., Zhang et al. (2011) over China and Queen et al. (2008) and Wu et al. (2008) over other regions). Overall, our results are generally consistent with the $36 \mathrm{~km}$ and $12 \mathrm{~km}$ simulation results in the MM5 model evaluation study over eastern China by Zhang et al. (2011).

\subsubsection{Domain-wide PM predictions at $36 \mathrm{~km}$ and $12 \mathrm{~km}$ grid resolutions}

Figure 4a shows the overlay of the simulated and observed monthly concentrations of $\mathrm{PM}_{2.5}$ and $\mathrm{PM}_{10}$ of the 74 cities in Domain 1 in January and February 2013. The corresponding performance statistics are shown in Table 3, including the MFBs and MFEs, which are recommended as the key statistical performance measures by US EPA (2007). In this guidance (US EPA, 2007), a satisfactory performance is indicated by an MFB within $\pm 60 \%$, and an MFE within $75 \%$ proposed by Boylan (2005), and an MFB within $\pm 50 \%$ and an MFE within $75 \%$ proposed by Morris et al. (2005). In this study, the MFBs within $\pm 60 \%$ and MFEs within $75 \%$ are considered to be satisfactory performance.

In January, the simulated results indicate two heavily polluted areas. One is the large area in the central east of China, including southern BTH, the YRD, nearly all the areas of Shandong, Henan, Anhui, Hubei, and Hunan provinces. The other one is located in the Sichuan Basin. The predicted $\mathrm{PM}_{2.5}$ concentrations in those areas are close to or higher than $150 \mu \mathrm{g} \mathrm{m}^{-3}$, which are much higher than the CNAAQS daily average $\mathrm{PM}_{2.5}$ standard of $75 \mu \mathrm{g} \mathrm{m}^{-3}$. The simulated $\mathrm{PM}_{10}$ concentrations in those areas show the same pattern as $\mathrm{PM}_{2.5}$ with values close to or higher than $200 \mu \mathrm{g} \mathrm{m}^{-3}$, which are much higher than the CNAAQS daily average $\mathrm{PM}_{10}$ standard of $150 \mu \mathrm{g} \mathrm{m}^{-3}$. In February, the heavily polluted area in the central east of China became smaller, only covering part of the BTH area, Shandong, Henan, and Hubei provinces. The heavily polluted area in the Sichuan Basin also becomes smaller in February, compared with January. Figure 4a shows that the predicted $\mathrm{PM}_{2.5}$ and $\mathrm{PM}_{10}$ agree well with the observations over the large, heavily polluted area in central east of China, and the PRD in both January and February. However, a notable underprediction occurs in northeastern and northwestern China, and some of the cities in the Sichuan Basin, consistent with previous studies (Liu et al., 2010a; Wang et al., 2010; L. T. Wang et al., 2012). This underprediction may be partially attributed to the spatial allocation of the emissions, and the lack of dust emissions. Several dust storm events were reported in northwest China in January 2013 (http://www.duststorm.com.cn/), which contributed to observed PM concentrations that are not captured by CMAQ due to a lack of an online dust emission module. Other possible reasons for underpredictions lie in the underpredictions in secondary aerosols such as sulfate, ammonium, and 
Table 2. Performance statistics for meteorological predictions over Domain 1 at $36 \mathrm{~km}$ resolution and Domain 2 at 36 and $12 \mathrm{~km}$ resolutions.

\begin{tabular}{|c|c|c|c|c|c|c|c|c|c|c|c|c|c|c|c|c|c|c|c|}
\hline \multirow[t]{2}{*}{ Variable* } & & \multicolumn{6}{|c|}{$36 \mathrm{~km}$ (Domain 1) } & \multicolumn{6}{|c|}{$36 \mathrm{~km}$ (Domain 2) } & \multicolumn{6}{|c|}{$12 \mathrm{~km}$ (Domain 2) } \\
\hline & & Obs. & Sim. & MB & RMSE & $\begin{array}{r}\mathrm{NMB} \\
(\%)\end{array}$ & $\begin{array}{l}\text { NME } \\
(\%)\end{array}$ & Obs. & Sim. & MB & RMSE & $\begin{array}{r}\mathrm{NMB} \\
(\%)\end{array}$ & $\begin{array}{r}\mathrm{NME} \\
(\%)\end{array}$ & Obs. & Sim. & MB & RMSE & $\begin{array}{r}\mathrm{NMB} \\
(\%)\end{array}$ & $\begin{array}{r}\mathrm{NME} \\
(\%)\end{array}$ \\
\hline \multirow[t]{2}{*}{$\mathrm{T} 2\left({ }^{\circ} \mathrm{C}\right)$} & Jan & -2.2 & -3.6 & -1.5 & 3.9 & -69.4 & 136.0 & -3.9 & -5.1 & -1.2 & 2.9 & -30.1 & 57.3 & -3.9 & -5.0 & -1.1 & 2.9 & -27.8 & 57.3 \\
\hline & Feb & 1.7 & 0.3 & -1.5 & 3.9 & -84.7 & 164.0 & -0.4 & -1.5 & -1.0 & 2.6 & -242.9 & 465.9 & -0.4 & -1.3 & -0.9 & 2.5 & -212.3 & 460.3 \\
\hline \multirow[t]{2}{*}{$\mathrm{RH} 2(\%)$} & Jan & 66.0 & 65.3 & -0.7 & 28.9 & -1.1 & 33.3 & 68.7 & 60.4 & -8.3 & 23.6 & -12.1 & 27.9 & 68.7 & 60.1 & -8.6 & 23.5 & -12.6 & 27.9 \\
\hline & Feb & 64.1 & 63.6 & -0.5 & 27.9 & -0.8 & 33.7 & 65.7 & 57.8 & -7.9 & 22.6 & -12.1 & 27.8 & 65.7 & 57.7 & -8.0 & 22.5 & -12.2 & 27.7 \\
\hline \multirow[t]{2}{*}{$\mathrm{WS} 10\left(\mathrm{~m} \mathrm{~s}^{-1}\right)$} & Jan & 2.3 & 2.9 & 0.6 & 2.1 & 27.4 & 69.8 & 2.3 & 2.8 & 0.5 & 0.8 & 23.2 & 60.4 & 2.3 & 2.9 & 0.6 & 1.9 & 26.7 & 62.0 \\
\hline & Feb & 2.5 & 3.4 & 0.8 & 2.2 & 33.8 & 65.2 & 2.7 & 3.4 & 0.7 & 2.0 & 24.2 & 54.2 & 2.7 & 3.4 & 0.7 & 2.0 & 26.7 & 55.3 \\
\hline \multirow[t]{2}{*}{ WD10 (degree) } & Jan & 196.6 & 186.6 & -10.0 & 134.2 & -5.1 & 46.4 & 198.7 & 205.9 & 7.1 & 123.6 & 3.6 & 39.4 & 198.7 & 198.8 & 0.1 & 122.2 & 0.1 & 38.4 \\
\hline & Feb & 191.3 & 178.4 & -12.9 & 125.5 & -6.8 & 43.1 & 184.1 & 181.4 & -2.7 & 116.4 & -1.5 & 37.9 & 184.1 & 176.0 & -8.1 & 117.8 & -4.4 & 37.9 \\
\hline \multirow[t]{2}{*}{ Precipitation (mm) } & Jan & 1.3 & 0.9 & -0.4 & 2.4 & -31.6 & 116.5 & 2.2 & 1.3 & -1.0 & 2.9 & -43.9 & 140.1 & 2.2 & 1.2 & -1.0 & 3.0 & -44.2 & 141.6 \\
\hline & Feb & 2.1 & 2.0 & -0.2 & 3.5 & -7.2 & 181.0 & 2.2 & 1.4 & -0.8 & 2.7 & -34.7 & 133.9 & 2.2 & 1.4 & -0.8 & 2.7 & -36.7 & 133.1 \\
\hline
\end{tabular}

Table 3. Performance statistics of $\mathrm{PM}_{2.5}$ and $\mathrm{PM}_{10}$ concentrations over Domain 1 at $36 \mathrm{~km}$ resolution and Domain 2 at 36 and $12 \mathrm{~km}$ resolutions.

\begin{tabular}{|c|c|c|c|c|c|c|c|c|c|}
\hline \multirow[b]{2}{*}{ Statistics } & \multicolumn{3}{|c|}{ 14-31 Jan 2013} & \multicolumn{3}{|c|}{ 1-28 Feb 2013} & \multicolumn{3}{|c|}{14 Jan-28 Feb 2013} \\
\hline & $36 \mathrm{~km}$ & $36 \mathrm{~km}$ & $12 \mathrm{~km}$ & $36 \mathrm{~km}$ & $36 \mathrm{~km}$ & $12 \mathrm{~km}$ & $36 \mathrm{~km}$ & $36 \mathrm{~km}$ & $12 \mathrm{~km}$ \\
\hline & (Domain 1) & (Domain 2) & (Domain 2) & (Domain 1) & (Domain 2) & (Domain 2) & (Domain 1) & (Domain 2) & (Domain 2) \\
\hline \multicolumn{10}{|l|}{$\mathrm{PM}_{2.5}$} \\
\hline Obs. $\left(\mu \mathrm{g} \mathrm{m}^{-3}\right)$ & 132.5 & 156.8 & 156.8 & 83.5 & 100.7 & 100.7 & 102.2 & 121.8 & 121.8 \\
\hline Sim. $\left(\mu \mathrm{g} \mathrm{m}^{-3}\right)$ & 117.9 & 142.0 & 175.9 & 75.3 & 93.2 & 116.5 & 91.6 & 111.7 & 138.9 \\
\hline $\operatorname{MB}\left(\mu \mathrm{g} \mathrm{m}^{-3}\right)$ & -14.6 & -14.8 & 19.1 & -8.1 & -7.5 & 15.8 & -10.6 & -10.1 & 17.1 \\
\hline $\operatorname{NMB}(\%)$ & -11.0 & -3.8 & 12.2 & -9.7 & -1.7 & 15.7 & -10.4 & -2.5 & 14.0 \\
\hline NME (\%) & 51.3 & 45.2 & 54.2 & 54.8 & 49.9 & 60.6 & 53.1 & 47.8 & 57.9 \\
\hline MFB ( \%) & -19.5 & -4.3 & 8.7 & -14.1 & 0.7 & 14.1 & -16.2 & -1.2 & 12.1 \\
\hline $\operatorname{MFE}(\%)$ & 58.3 & 46.8 & 51.1 & 62.1 & 51.9 & 56.8 & 60.6 & 50.0 & 54.7 \\
\hline \multicolumn{10}{|l|}{$\mathrm{PM}_{10}$} \\
\hline Obs. $\left(\mu \mathrm{g} \mathrm{m}^{-3}\right)$ & 189.9 & 232.5 & 232.5 & 119.6 & 147.3 & 147.3 & 147.1 & 179.7 & 179.7 \\
\hline Sim. $\left(\mu \mathrm{g} \mathrm{m}^{-3}\right)$ & 129.0 & 156.8 & 200.8 & 81.8 & 103.2 & 131.9 & 100.3 & 124.0 & 158.2 \\
\hline $\mathrm{MB}\left(\mu \mathrm{g} \mathrm{m}^{-3}\right)$ & -60.8 & -75.7 & -31.6 & -37.8 & -44.2 & -15.4 & -46.8 & -55.6 & -21.5 \\
\hline $\operatorname{NMB}(\%)$ & -32.0 & -28.9 & -13.6 & -31.6 & -26.0 & -10.4 & -31.8 & -27.2 & -12.0 \\
\hline NME (\%) & 51.0 & 45.7 & 49.5 & 55.1 & 50.7 & 56.9 & 53.0 & 48.4 & 53.3 \\
\hline $\operatorname{MFB}(\%)$ & -43.3 & -28.3 & -16.0 & -38.6 & -26.0 & -11.5 & -40.4 & -26.9 & -13.2 \\
\hline $\operatorname{MFE}(\%)$ & 65.2 & 53.3 & 52.7 & 67.8 & 57.1 & 58.7 & 66.8 & 55.7 & 56.4 \\
\hline
\end{tabular}

secondary organic aerosols due to the limitations of model treatments. For example, heterogeneous chemistry of $\mathrm{SO}_{2}$ on the surface of particles is not treated in CMAQ, which contributes significantly to the formation of sulfate when the surface of particles is large (e.g., Zhang and Carmichael, 1999; K. Wang et al., 2009).

As shown in Table 3, the model overall underpredicts $\mathrm{PM}_{2.5}$ and $\mathrm{PM}_{10}$ concentrations over Domain 1. The domainwide NMBs for $\mathrm{PM}_{2.5}$ are $-11.0 \%$ and $-9.7 \%$ for January and February, respectively. The MFBs and MFEs are $-19.5 \%$ and $58.5 \%$ for January, and $-14.1 \%$ and $62.1 \%$ for February, respectively. All of them are within the criteria for a satisfactory performance mentioned above. $\mathrm{PM}_{10}$ are more underpredicted, with NMBs of $-32.0 \%$ and $-31.6 \%$ for January and February, respectively. Figure $4 \mathrm{~b}$ shows the spatial distributions of the NMBs for $\mathrm{PM}_{2.5}$ and $\mathrm{PM}_{10}$ concentrations for the 74 cities. Despite the significant underpredictions for $\mathrm{PM}_{2.5}$ concentrations in northeastern and northwestern China in January, relatively few underpredictions occur in most of the cities in the BTH, the YRD, and the PRD regions. Possible reasons for these underpredictions include the biases in the meteorological predictions (e.g., the underprediction of temperature which leads to a lower photolysis rate in the formation of secondary inorganic and organic aerosols, and the overprediction of wind speed which blows off the pollutants), the uncertainties in the spatial allocation of the emissions, the lack of the dust emissions, and possible underestimations of emissions due to different base years of emission and simulation (2010 vs. 2013). The NMBs for the cities in the BTH area fall into the range of $-41.9 \%$ (Zhangjiakou) to $37.5 \%$ (Zhengzhou) with an average of $-14.0 \%$. The best agreement appears in Qinhuangdao $(-3.8 \%)$, Handan $(5.3 \%)$, and Cangzhou $(6.5 \%)$. In the YRD and PRD regions, the average NMBs are $-2.4 \%$ and $-11.8 \%$, respectively. Obvious overpredictions occur in central China along the Yangtze River with the NMBs of $18.4 \%$ (Changsha) to $224 \%$ (Guiyang). The spatial distributions of NMBs of $\mathrm{PM}_{2.5}$ and $\mathrm{PM}_{10}$ in February are quite similar to 
those in January except for overpredictions in some cities in the PRD regions. The average NMBs for the cities in the $\mathrm{BTH}$, the YRD, and PRD regions are $-17.1 \%,-7.4 \%$, and $-5.4 \%$, respectively. The spatial distributions of NMBs for $\mathrm{PM}_{10}$ concentrations are generally similar to those of $\mathrm{PM}_{2.5}$. The average NMBs for the cities in the BTH, the YRD, and the PRD regions in January are $-37.9 \%,-18.5 \%$, and $-25.1 \%$, respectively. The corresponding values for February are $-38.2 \%,-19.7 \%$, and $18.0 \%$, respectively. Compared with $\mathrm{PM}_{2.5}$, the larger biases of $\mathrm{PM}_{10}$ are mainly attributed to the lack of the dust emissions, which contribute to a large faction of coarse particles.

Figure 5a presents the predicted $\mathrm{PM}_{2.5}$ and $\mathrm{PM}_{10}$ concentrations from the $12 \mathrm{~km}$ simulation in Domain 2 overlaid with observations in January and February, 2013. The corresponding performance statistics are shown in Table 3 . The simulations indicate an extremely severe pollution occurring in January over Beijing, Tianjin, southern Hebei, most of Henan, and the western areas of Shandong and Anhui provinces. The monthly average $\mathrm{PM}_{2.5}$ concentrations over those areas are higher than $150 \mu^{-3} \mathrm{~m}^{-3}$, which is twice the new CNAAQS standard for daily $\mathrm{PM}_{2.5}$ concentrations. The concentrations in February are much lower, with the highest concentrations in southern Hebei, northern Henan, and some western areas of Shandong. The pollution pattern of $\mathrm{PM}_{10}$ is similar to that of $\mathrm{PM}_{2.5}$; with the concentrations in the heavily polluted area over $200 \mu \mathrm{g} \mathrm{m}^{-3}$, which is also higher than the CNAAQS daily standard for $\mathrm{PM}_{10}$.

Overall, predictions agree well with the observations, especially in the heavily polluted areas. Nonetheless, it should be noted that the observations at some sites are significantly higher than $200 \mu \mathrm{g} \mathrm{m}^{-3}$ during that period, which can be reflected clearly in the spatial distributions of NMBs shown in Fig. 5b. The model significantly underpredicts $\mathrm{PM}_{2.5}$ and $\mathrm{PM}_{10}$ concentrations over the three cities in southern Hebei in both January and February, with NMBs of $-36.4 \%$ to $35.3 \%$ in January and $-35.9 \%$ to $-1.7 \%$ in February. In the megacities such as Beijing and Tianjin, large overpredictions and large underpredictions occur at those sites that are close to each other, indicating that the model fails to capture the spatial distribution of observed concentrations in the two-city cluster region. In general, the concentrations at the urban sites are overpredicted and those at the rural sites are underpredicted. The observed concentrations are relatively uniform over those sites compared to predictions. The discrepancy between the spatial distributions of predictions and observations may be partially attributed to the uncertainties in the spatial allocation of emissions used. For example, some sources are spatially distributed into the grids using the population density as a surrogate; however, most of the industrial manufacturers in Beijing have been moved out of the urban areas in recent years, leading to inconsistencies between the actual and estimated spatial distributions of the emissions. The averaged NMBs for $\mathrm{PM}_{2.5}$ of Beijing, Tianjin, Shijiazhuang, Xingtai, and Handan are $-8.2 \%$,
$40.6 \%, 0.8 \%,-18.4 \%$, and $8.8 \%$ in January, and $9.4 \%$, $27.3 \%,-19.5 \%,-13.9 \%$, and $-5.6 \%$ in February, respectively. Notable overpredictions can be found in the area of the YRD, especially for $\mathrm{PM}_{2.5}$. The averaged NMBs in the cities in YRD for $\mathrm{PM}_{2.5}$ are $20.6 \%$ and $26.2 \%$ for January and February, respectively. The domain-wide NMBs for $\mathrm{PM}_{2.5}$ at $12 \mathrm{~km}$ resolution are $12.2 \%$ for January and $15.7 \%$ for February, and the MFBs and MFEs are $8.7 \%$ and $51.1 \%$ for January and $14.1 \%$ and $56.8 \%$ for February, respectively.

As shown in Table 3, the domain-wide NMBs for $\mathrm{PM}_{10}$ over Domain 2 are $-13.6 \%$ and $-10.4 \%$ for January and February, respectively. The spatial distributions of the NMBs for $\mathrm{PM}_{10}$ are similar to those of $\mathrm{PM}_{2.5}$ in the $\mathrm{BTH}$ area. The averaged values for Beijing, Tianjin, Shijiazhuang, Xingtai, and Handan are $-11.5 \%, 0.5 \%,-37.8 \%,-47.0 \%$, and $-22.9 \%$ for January, and $7.3 \%, 7.7 \%,-39.5 \%,-42.2 \%$, and $-29.4 \%$ for February, respectively. In the YRD region, different from $\mathrm{PM}_{2.5}$ concentrations that are overpredicted at nearly all sites, $\mathrm{PM}_{10}$ concentrations at some sites show slight to moderate underpredictions (NMBs of $-0.1 \%$ to $-34.4 \%$ ). The averaged NMBs in this area are $-15.3 \%$ for January and $-0.8 \%$ for February.

Table 3 also compares the model performance statistics for hourly $\mathrm{PM}_{2.5}$ and $\mathrm{PM}_{10}$ concentrations over Domain 2 from the simulations at 36 and $12 \mathrm{~km}$ grid resolutions. $\mathrm{PM}_{2.5}$ concentrations are overall slightly underpredicted at the $36 \mathrm{~km}$ resolution compared with overpredictions at the $12 \mathrm{~km}$ resolution. The domain-average NMBs and MFBs are $-2.5 \%$ and $-1.2 \%$ at $36 \mathrm{~km}$, and $14.0 \%$ and $12.1 \%$ at $12 \mathrm{~km}$ for the whole period 14 January to 28 February, respectively. NMEs and MFEs are $47.8 \%$ and $50.0 \%$ at $36 \mathrm{~km}$, and $57.9 \%$ and $54.7 \%$ at $12 \mathrm{~km}$. They are all within the benchmarks of MFBs $< \pm 60 \%$ and MFEs $<75 \%$. $\mathrm{PM}_{10}$ concentrations are underpredicted at both grid resolutions, with NMBs and MFBs of $-27.2 \%$ and $-26.9 \%$ at $36 \mathrm{~km}$, and $-12.0 \%$ and $-13.2 \%$ at $12 \mathrm{~km}$, respectively. NMEs and MFEs are $48.4 \%$ and $55.7 \%$ at $36 \mathrm{~km}$, and $53.3 \%$ and $56.4 \%$ at $12 \mathrm{~km}$, respectively. While the use of a finer grid resolution changes $\mathrm{PM}_{2.5}$ performance from a slight underprediction to a moderate overprediction, it notably reduces the underpredictions in $\mathrm{PM}_{10}$.

\subsubsection{Site-specific PM predictions at the $12 \mathrm{~km}$ grid resolution}

Table 4 summarizes the MFBs and MFEs for the hourly $\mathrm{PM}_{2.5}$ concentrations in the representative cities in Domain 2. For the three cities, Shijiazhuang, Xingtai, and Handan, the MFBs and MFEs are within the recommended benchmarks at all sites. For Beijing, as discussed previously, overpredictions occur at the urban sites and underpredictions occur at the rural sites for both January and February. MFBs and MFEs at several sites are beyond the criteria. Nevertheless, the MFBs and MFEs for the average hourly $\mathrm{PM}_{2.5}$ concentrations in Beijing are $-14.2 \%$ and $51.8 \%$ in January, and $12.8 \%$ and 

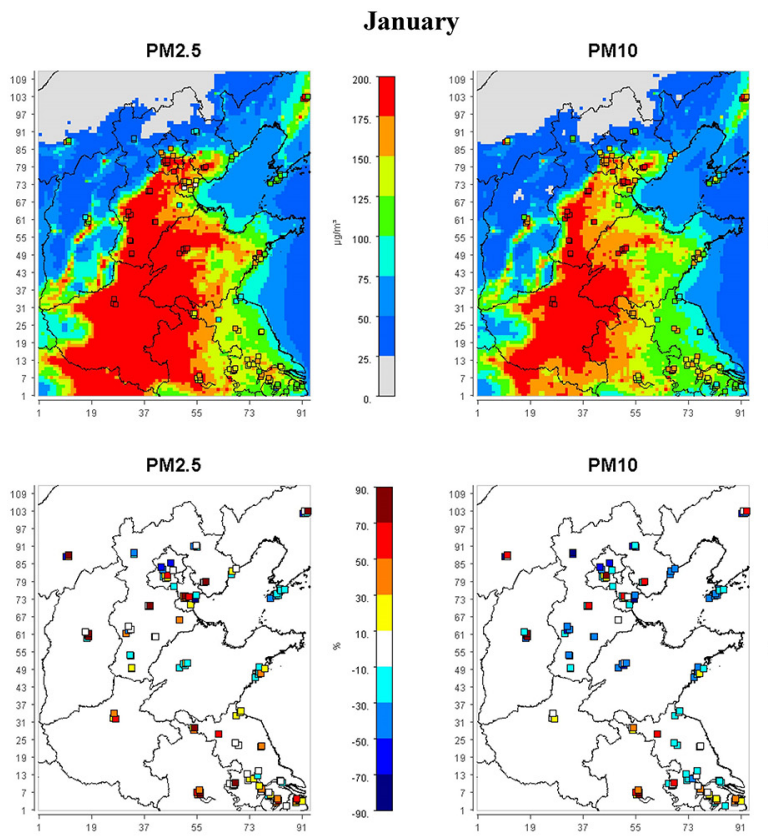

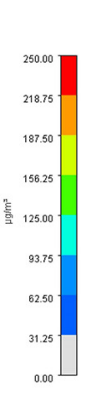

(a)
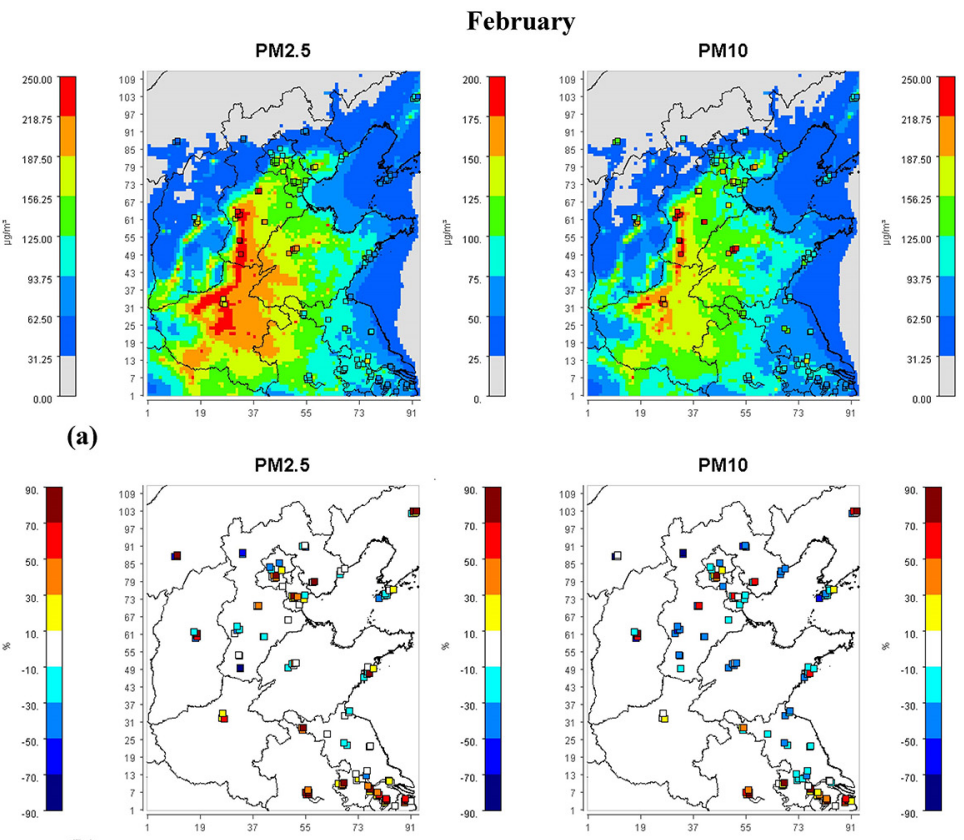

Fig. 5. (a) Overlay of the simulated and observed monthly-average concentrations of $\mathrm{PM}_{2.5}$ and $\mathrm{PM}_{10}$ of the reported 235 sites and (b) the corresponding spatial distributions of NMBs for $\mathrm{PM}_{2.5}$ and $\mathrm{PM}_{10}$ at the $12 \mathrm{~km}$ horizontal grid resolution for January and February, 2013. Note the average for January is from 14 January to 31 January. Square signs indicate the observations.

$61.2 \%$ in February, respectively. This may imply that the total amount of the emissions in Beijing is well estimated in terms of performance statistics using the MEIC emission inventory, despite the uncertainties in the spatial allocation of those emissions.

The overall performance in Tianjin is much better than that in Beijing, as the MFBs and MFEs at all sites except for one urban site are within benchmarks. In general, the $\mathrm{PM}_{2.5}$ concentrations in Tianjin are overpredicted. In Taiyuan, significant overpredictions occur at the two urban sites and underpredictions occur at one urban and one rural site. This may be partially attributed to the uncertainties in spatial allocation of emissions, as discussed previously. The model predictions agree well for the other two capital cities, Zhengzhou and Jinan, with all the statistics at all sites satisfying the criteria.

\subsubsection{Temporal variations of PM in the three cities in southern Hebei}

To further evaluate model performance for the three most polluted cities in southern Hebei of major concerns (i.e., Shijiazhuang, Xingtai, and Handan) and to understand the formation mechanisms of PM underlying the heavy pollution episodes, the hourly $\mathrm{PM}_{2.5}$ and $\mathrm{PM}_{10}$ concentrations from the $12 \mathrm{~km}$ simulation are compared with observations. The model's capability to capture the temporal variations of the $\mathrm{PM}_{2.5}$ and $\mathrm{PM}_{10}$ concentrations in the three cities are discussed below.

\section{Shijiazhuang}

Figure 6a-d shows the temporal variations of the observed and simulated hourly $\mathrm{PM}_{2.5}$ concentrations at the four monitoring sites in Shijiazhuang. The observations indicate the occurrence of several very severe pollution episodes during the period 14 January to 28 February. The maximum hourly $\mathrm{PM}_{2.5}$ and $\mathrm{PM}_{10}$ concentrations reached as high as 756 and $1239 \mathrm{\mu g} \mathrm{m}^{-3}$, respectively, both at an urban site (the Central Hospital). A persistent, extremely severe pollution event occurred during the period 15-30 January. During this time period, the concentrations rapidly built up in a very short time and resulted in five high-pollution episodes in 15 days, each persisting 2-5 days. However, the situation in February was somewhat different, with significantly lower concentrations during most days and less frequent pollution episodes (each lasting about 3-5 days). The observed average concentrations of $\mathrm{PM}_{2.5}$ at the four sites were $258.2 \mu \mathrm{g} \mathrm{m}^{-3}$ in January and $210.4 \mu \mathrm{g} \mathrm{m}^{-3}$ in February, respectively, with both higher by factors of 2.44 and 1.81, respectively, than the daily standard for $\mathrm{PM}_{2.5}$. The model well reproduces the $\mathrm{PM}_{2.5}$ concentrations at the two rural sites in Shijiazhuang. At the urban site of the Century Park, the model predictions generally agree with the observations, but a relatively better performance can be found in February than in January. At the urban site of the Central Hospital, $\mathrm{PM}_{2.5}$ concentrations are significantly underpredicted, especially during the heavily polluted period in January. This underprediction may be attributed 
Table 4. MFBs and MFEs for hourly $\mathrm{PM}_{2.5}$ concentrations simulated at the $12 \mathrm{~km}$ grid resolution in the representative cities.

\begin{tabular}{|c|c|c|c|c|c|c|c|c|c|}
\hline \multirow[b]{2}{*}{ City/Site location } & \multicolumn{3}{|c|}{ 14-31 January } & \multicolumn{3}{|c|}{ 1-28 February } & \multicolumn{3}{|c|}{1 January-28 February } \\
\hline & $n$ & $\begin{array}{r}\text { MFB } \\
(\%)\end{array}$ & $\begin{array}{r}\text { MFE } \\
(\%)\end{array}$ & $n$ & $\begin{array}{r}\text { MFB } \\
(\%)\end{array}$ & $\begin{array}{r}\text { MFE } \\
(\%)\end{array}$ & $n$ & $\begin{array}{r}\text { MFB } \\
(\%)\end{array}$ & $\begin{array}{r}\text { MFE } \\
(\%)\end{array}$ \\
\hline \multicolumn{10}{|l|}{ Shijiazhuang } \\
\hline Urban (Century Park) & 427 & -2.8 & 49.7 & 669 & -6.9 & 45.1 & 1096 & -5.4 & 46.9 \\
\hline Urban (Central Hospital) & 425 & -40.2 & 60.4 & 669 & -37.1 & 50.7 & 1094 & -38.3 & 54.4 \\
\hline Rural (Fenglong Mountain) & 270 & 54.5 & 61.7 & 657 & 7.2 & 46.1 & 927 & 21.0 & 50.6 \\
\hline Rural (Northwest Headwater) & 427 & 11.3 & 52.8 & 663 & -6.9 & 47.1 & 1090 & 0.2 & 49.3 \\
\hline \multicolumn{10}{|l|}{ Xingtai } \\
\hline Urban (Normal Senior High School) & 427 & -22.6 & 40.5 & 669 & -18.6 & 36.4 & 1096 & -20.1 & 38.0 \\
\hline Rural (Dahuoquan) & 392 & -15.1 & 39.7 & 620 & 0.9 & 45.4 & 1012 & -5.3 & 43.2 \\
\hline \multicolumn{10}{|l|}{ Handan } \\
\hline Urban (Handan EPB) & 427 & 1.3 & 35.9 & 669 & 0.2 & 37.7 & 1096 & 0.6 & 37.0 \\
\hline Rural (Wastewater Treatment Plant) & 274 & 8.0 & 27.8 & & & & 274 & 8.1 & 27.8 \\
\hline Urban (HEBEU) & $694^{\mathrm{a}}$ & $9.8^{\mathrm{a}}$ & $47.3^{\mathrm{a}}$ & 572 & 22.3 & 46.3 & $1266^{\mathrm{b}}$ & $15.5^{\mathrm{b}}$ & $46.8^{\mathrm{b}}$ \\
\hline \multicolumn{10}{|l|}{ Beijing } \\
\hline Urban (Dongsi) & 351 & $66.5^{\mathrm{c}}$ & 73.0 & 664 & $81.0^{\mathrm{c}}$ & $92.8^{\mathrm{c}}$ & 1015 & $76.0^{\mathrm{c}}$ & $85.9^{\mathrm{c}}$ \\
\hline Urban (Gucheng) & 351 & -8.3 & 54.5 & 658 & 15.1 & 66.5 & 1009 & 7.0 & 62.3 \\
\hline Urban (Guangyuan) & 351 & 35.6 & 59.9 & 664 & 47.2 & $77.5^{\mathrm{c}}$ & 1015 & 43.2 & 71.4 \\
\hline Urban (Tiantan) & 351 & 33.6 & 63.1 & 652 & 57.3 & $81.0^{\mathrm{c}}$ & 1003 & 49.0 & 74.7 \\
\hline Urban (Wanshousi) & 349 & 12.5 & 59.7 & 657 & 35.5 & $75.8^{\mathrm{c}}$ & 1006 & 27.5 & 70.2 \\
\hline Rural (Changping) & 351 & -29.1 & 61.9 & 660 & -8.8 & 64.6 & 1011 & -15.9 & 63.7 \\
\hline Rural (Dingling) & 261 & -51.0 & 71.6 & 625 & -24.5 & 62.2 & 886 & -32.3 & 65.0 \\
\hline Rural (Huairou) & 350 & $-68.1^{\mathrm{c}}$ & $81.7^{\mathrm{c}}$ & 659 & -42.8 & 75.0 & 1009 & -51.5 & $77.4^{\mathrm{c}}$ \\
\hline Rural (Shunyi) & 344 & 12.6 & 58.2 & 659 & 38.3 & 69.4 & 1003 & 29.5 & 65.6 \\
\hline \multicolumn{10}{|l|}{ Tianjin } \\
\hline Urban (Tianshanlu) & 427 & $69.2^{\mathrm{c}}$ & 73.8 & 669 & $76.7^{\mathrm{c}}$ & $85.9^{\mathrm{c}}$ & 1096 & $73.8^{\mathrm{c}}$ & $81.2^{\mathrm{c}}$ \\
\hline Urban (Tianjin Relay Plant) & 423 & 30.3 & 46.2 & 666 & 32.2 & 56.0 & 1089 & 31.5 & 52.2 \\
\hline Urban (Nanjinglu) & 427 & 32.2 & 50.7 & 669 & 26.9 & 54.9 & 1096 & 29.0 & 53.3 \\
\hline Urban (Environmental Monitoring Center) & 369 & 31.8 & 48.0 & 644 & 39.6 & 57.9 & 1013 & 36.7 & 54.3 \\
\hline Rural (Airport) & 427 & 37.3 & 54.6 & 431 & 45.5 & 60.8 & 858 & 41.5 & 57.7 \\
\hline Rural (Industrial Park) & & & & 369 & 31.5 & 51.6 & 369 & 31.5 & 51.6 \\
\hline Rural (Yongminglu) & 346 & 17.2 & 45.9 & 538 & 14.6 & 42.8 & 884 & 15.6 & 44.0 \\
\hline Rural (Eco-city) & 307 & -4.7 & 49.0 & 644 & -18.1 & 54.7 & 951 & -13.8 & 52.8 \\
\hline \multicolumn{10}{|l|}{ Taiyuan } \\
\hline Urban (Jianhe) & 427 & $102.9^{c}$ & $105.7^{\mathrm{c}}$ & 669 & $88.7^{\mathrm{c}}$ & $96.6^{\mathrm{c}}$ & 1096 & $94.2^{\mathrm{c}}$ & $100.1^{\mathrm{c}}$ \\
\hline Urban (Wucheng) & 380 & $91.7^{\mathrm{c}}$ & $92.2^{\mathrm{c}}$ & 595 & 54.7 & 73.9 & 975 & $69.1^{\mathrm{c}}$ & $81.0^{\mathrm{c}}$ \\
\hline Urban (Taoyuan) & 427 & -51.0 & 71.4 & 669 & -39.1 & $78.0^{\mathrm{c}}$ & 1096 & -43.8 & $75.5^{\mathrm{c}}$ \\
\hline Rural (Jinyuan) & 427 & -39.4 & 66.3 & 669 & -38.4 & $75.8^{\mathrm{c}}$ & 1096 & -38.9 & 72.2 \\
\hline Rural (Shanglan) & 420 & 1.6 & 70.3 & 652 & -10.4 & 70.1 & 1072 & -5.8 & 70.2 \\
\hline \multicolumn{10}{|l|}{ Zhengzhou } \\
\hline Urban (No.47 Middle School) & 427 & 48.2 & 52.5 & 669 & 45.7 & 53.6 & 1096 & 46.6 & 53.1 \\
\hline Urban (Water Supply Plant) & 427 & 25.0 & 38.4 & 669 & 27.2 & 42.4 & 1096 & 26.3 & 40.8 \\
\hline Rural (Gangli Reservior) & 417 & 30.2 & 43.9 & 657 & 29.4 & 47.1 & 1074 & 29.6 & 45.8 \\
\hline \multicolumn{10}{|l|}{ Jinan } \\
\hline Urban (Environmental Monitoring Center) & 427 & 14.1 & 36.6 & 669 & 30.2 & 59.8 & 1096 & 23.9 & 50.8 \\
\hline Urban (Economic Development Region) & 427 & -14.9 & 40.0 & 657 & 2.8 & 46.9 & 1084 & -4.1 & 44.2 \\
\hline Urban (Kegansuo) & 421 & -19.6 & 40.4 & 586 & -3.9 & 40.2 & 1007 & -10.4 & 40.3 \\
\hline Urban (Academy of Agricultural Science) & 427 & -20.9 & 42.3 & 666 & -5.4 & 43.9 & 1093 & -11.5 & 43.3 \\
\hline Rural (Changqing) & 427 & -23.4 & 46.1 & 650 & -21.9 & 41.2 & 1077 & -22.5 & 43.1 \\
\hline
\end{tabular}

a These statistics are for 1-31 January. ${ }^{\mathrm{b}}$ These statistics are for 1 January-28 February. $n$ - number of data pairs.

$\mathrm{c}$ MFB $> \pm 60 \%$ and MFE $>75 \%$ are considered to indicate a relatively poor performance in this study. 

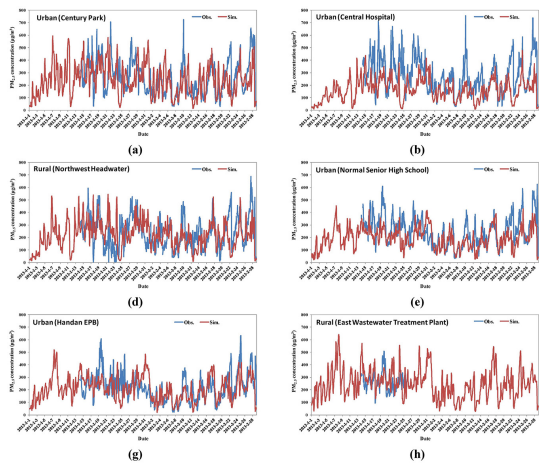

(e)
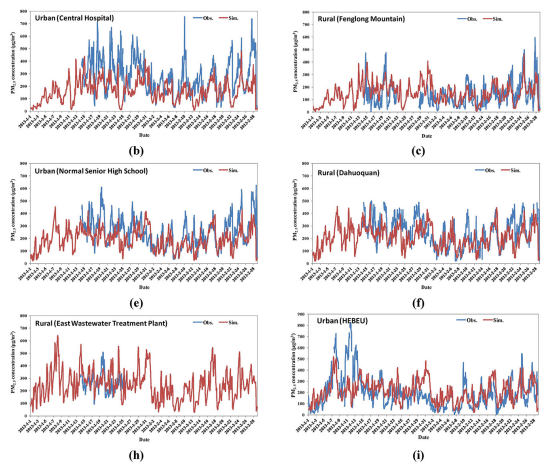

Fig. 6. The temporal variations of the observed and simulated $\mathrm{PM}_{2.5}$ concentrations at the monitoring sites in Shijiazhuang, Xingtai, and Handan in January and February, 2013. (a-d) are the sites in Shijiazhuang, $(\mathbf{e}, \mathbf{f})$ are the sites in Xingtai, and $(\mathbf{g}-\mathbf{i})$ are the sites in Handan.

to the uncertainties in the estimation of the local emissions (note that Shijiazhuang still has many chemical and pharmaceutical industrial manufacturers within or close to the urban areas, which is different from Beijing), the uncertainties and limitations of the model treatments in the formation and accumulation of secondary aerosols under high humidity conditions during that episode, as well as the uncertainties in the meteorological predictions (e.g., large cold bias in near-surface temperatures). In particular, in Y. X. Wang et al.'s (2013) study, sulfate and nitrate aerosols in $\mathrm{PM}_{2.5}$ in Beijing were observed to be as high as $60-100 \mu \mathrm{g} \mathrm{m}^{-3}$ and $30-50 \mu \mathrm{g} \mathrm{m}^{-3}$, respectively, on daily average during the period 11-15 January 2013, while in this work the corresponding sulfate and nitrate concentrations predicted in Beijing are 14-29 $\mu \mathrm{g} \mathrm{m}^{-3}$ and 13-33 $\mu \mathrm{g} \mathrm{m}^{-3}$, respectively. The significant underpredictions indicate the deficiency of the model in treating the heterogeneous chemistry (e.g., missing the heterogeneous reactions of $\mathrm{SO}_{2}$ to form $\mathrm{SO}_{4}^{2-}$ ) that contribute significantly to the formation of secondary inorganic species on the surface of existing particles such as dust (K. Wang et al., 2009).

The $\mathrm{PM}_{10}$ concentrations are overall significantly underpredicted, as shown in Fig. 7a-d, especially for the extremely polluted period, 15 to 30 January. This underprediction may be attributed to the lack of the dust emissions, the underestimation of emissions due to different base years of emission and simulation, and the uncertainties in the meteorological predictions (e.g., the overprediction of wind speed) during the extremely polluted period. MFBs and MFEs for the $\mathrm{PM}_{10}$ concentrations during the entire period 14 January to 28 February are $-41.6 \%$ and $61.8 \%$ at the Century Park, $-66.6 \%$ and $73.0 \%$ at the Central Hospital, $-27.6 \%$ and $52.0 \%$ at Fenglong Mountain, and $-41.8 \%$ and $57.3 \%$ at the Northwest Headwater, respectively.
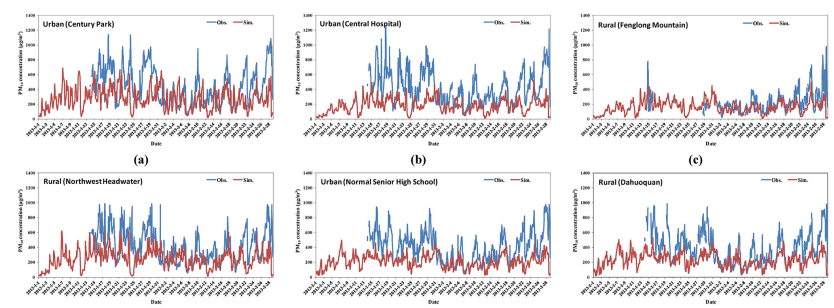

(d)
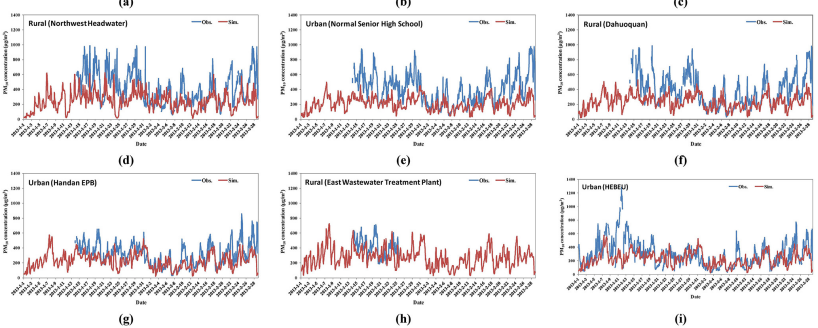

Fig. 7. The temporal variations of the observed and simulated $\mathrm{PM}_{10}$ concentrations at the monitoring sites in Shijiazhuang, Xingtai, and Handan in January and February, 2013. (a-d) are the sites in Shijiazhuang, $(\mathbf{e}, \mathbf{f})$ are the sites in Xingtai, and $(\mathbf{g}-\mathbf{i})$ are the sites in Handan.

\section{Xingtai}

Figures $6 \mathrm{e}$ and $\mathrm{f}$ and $7 \mathrm{e}$ and $\mathrm{f}$ compare the temporal variations of the observed and simulated $\mathrm{PM}_{2.5}$ and $\mathrm{PM}_{10}$ concentrations at the two sites in Xingtai. The observed average concentrations of $\mathrm{PM}_{2.5}$ at the two sites were $296.8 \mu \mathrm{g} \mathrm{m}^{-3}$ in January and $216.9 \mathrm{\mu g} \mathrm{m}^{-3}$ in February, respectively. The predictions of $\mathrm{PM}_{2.5}$ concentrations in Xingtai overall agree well with the observations, at both urban and rural sites, especially in February. The MFBs and MFEs during the entire period for $\mathrm{PM}_{2.5}$ are $-20.1 \%$ and $38.0 \%$ at the urban site, and $-5.3 \%$ and $43.2 \%$ at the rural site, respectively (see Table 4). The six observed pollution episodes in February are clearly reproduced. However, the $\mathrm{PM}_{10}$ concentrations are significantly underpredicted at both sites for the same reasons mentioned previously, which is similar to the $\mathrm{PM}_{10}$ concentrations in Shijiazhuang. The MFBs and MFEs during the entire period for $\mathrm{PM}_{10}$ are $-54.4 \%$ and $61.8 \%$ at the urban site, and $-42.3 \%$ and $57.3 \%$ at the rural site, respectively.

\section{Handan}

Figures $6 \mathrm{~g}-\mathrm{i}$ and $7 \mathrm{~g}-\mathrm{i}$ compare the temporal variations of the observed and predicted $\mathrm{PM}_{2.5}$ and $\mathrm{PM}_{10}$ concentrations at the three monitoring sites in Handan. The observed average concentrations of $\mathrm{PM}_{2.5}$ at the three sites were $248.7 \mu \mathrm{g} \mathrm{m}^{-3}$ in January and $179.5 \mu \mathrm{g} \mathrm{m}^{-3}$ in February, respectively. Very few observational data are available at the rural site (East Wastewater Treatment Plant) for model evaluation. At the urban site of Handan Environmental Protection Bureau (EPB), the model well reproduces the $\mathrm{PM}_{2.5}$ concentrations but the $\mathrm{PM}_{10}$ concentrations are slightly underpredicted. The MFBs and MFEs at this site are $0.6 \%$ and $37.0 \%$ for $\mathrm{PM}_{2.5}$ and $-28.7 \%$ and $40.2 \%$ for $\mathrm{PM}_{10}$, respectively (see Table 4). 
At the urban site of HEBEU, the observations indicate three extremely severe pollution episodes occurring on 7 9, 10-12 and 13-14 January. During the period 10-12 January the observed maximum hourly concentrations of $\mathrm{PM}_{2.5}$ and $\mathrm{PM}_{10}$ reached as high as 825 and $1281 \mu \mathrm{g} \mathrm{m}^{-3}$, respectively. The highest daily average $\mathrm{PM}_{2.5}$ concentration of $663.7 \mu \mathrm{g} \mathrm{m}^{-3}$ occurred on 11 January, which was 8.8 times the new CNAAQS. The model fails to reproduce the extremely high concentrations $\left(>600 \mu \mathrm{g} \mathrm{m}^{-3}\right.$ ) for all three episodes, although it does predict a high $\mathrm{PM}_{2.5}$ concentration of $500 \mu \mathrm{g} \mathrm{m}^{-3}$ on 8 January. The MFBs and MFEs at this site are $15.5 \%$ and $46.8 \%$, respectively. The observational data are only available at this site among the nine sites for the period 1 to 13 January, it is not clear if such large underpredictions also occur at the remaining eight sites. Possible reasons include the missing of episodic emissions from local sources, underestimating the regional transport from upwind regions (e.g., from NHB and SX when northwest winds dominate), and the neglect of heterogeneous chemistry on the surface of atmospheric particles that can increase the concentrations of secondary inorganic aerosols such as sulfate, nitrate, and ammonium (K. Wang et al., 2009). The temporal analyses showed clear differences in the observations for the two periods: 1-13 January when severe pollution episodes occurred with high $\mathrm{PM}_{2.5}$ and $\mathrm{PM}_{10}$ concentrations and 14-31 January when the observed $\mathrm{PM}_{2.5}$ and $\mathrm{PM}_{10}$ concentrations are much lower. Therefore, in the following sections, the source contributions of $\mathrm{PM}_{2.5}$ during the two time periods are examined and discussed separately.

\section{Source contributions to $\mathrm{PM}_{2.5}$ concentrations}

\subsection{Contributions by source regions}

Following L. T. Wang et al. (2012), the emission sources within the SHB are considered as local sources for the three cities of Shijiazhuang, Xingtai and Handan, and the sources outside the SHB are considered as regional sources. In this section, the source contributions to Shijiazhuang, Xingtai, and Handan from the six regions of interest are analyzed for January and February 2013, and compared with the results of L. T. Wang et al. (2012) for December 2007, the most polluted month during the period 2001 to 2010. In addition, the inter-influence of the three cities to the $\mathrm{PM}_{2.5}$ concentrations in each area are assessed.

\subsubsection{Shijiazhuang}

Table 5a shows the average contributions by source region to the $\mathrm{PM}_{2.5}$ concentrations in Shijiazhuang, Xingtai, and Handan for December 2007, and January and February 2013. The local sources (SHB) contribute $75.8 \%, 67.2 \%$, and $66.4 \%$ on average to $\mathrm{PM}_{2.5}$ in Shijiazhuang, during the period 113 and 14-31 January, and February, respectively, compared with $65.1 \%$ for December 2007. It is the largest contributor among the six source regions included during all four periods. The second largest contributor is the NHB for all periods in 2013, with source contributions of $9.0 \%$ for 1-13 January, $17.8 \%$ for $14-31$ January and $15.0 \%$ for February. However, for December 2007, SX is the second largest contributor, contributing to $14.1 \%$ of $\mathrm{PM}_{2.5}$ in Shijiazhuang. For 113 and 14-31 January and February 2013, the contributions of SX significantly decrease to $7.2 \%, 3.2 \%$, and $3.8 \%$, respectively. Relatively smaller contributions can be found for BJTJ, SD, and HN, but noticeable variations remain, for example, the contribution by BJTJ varies from $0.9 \%$ in December 2007 to $3.4 \%$ in 14-31 January 2013. The total regional contributions to the $\mathrm{PM}_{2.5}$ concentrations in Shijiazhuang are $24.6 \%$ in December 2007, $19.4 \%$ in 1-13 January, $27.5 \%$ in 14-31 January, and $27.8 \%$ in February. The contributions from the total sources outside Hebei are $10.5 \%$ in 1-13 January, $9.7 \%$ for $14-31$ January, and $12.8 \%$ for February, compared with $17.4 \%$ for December 2007.

For January 2013, the most polluted period, the higher contributions from the local sources are caused by a more stable atmosphere that favors the accumulation of the local pollutants than other regions. Figure 8 shows the average PBL height over Domain 2 for the four periods. During all the periods, PBL heights over the southern area of Hebei are the lowest within Domain 2. This indicates that even with the same emission densities as other cities, the southern Hebei cities may experience heavier air pollution than the others. This can be explained by the special terrain and local-scale meteorological phenomenon in this region, namely, the stable air blowing from the west crosses the Taihang Mountain, which sinks and meets the air blowing from the south or east directions over southern areas of Hebei. The convergence and confrontation of the two air flows result in a very stable atmosphere and accumulation of air pollutants (C. M. Wang et al., 2013). During the period 1-13 and 14-31 January there are large areas in southern Hebei, including Baoding, Shijiazhuang, and Xingtai, with the average PBL height of as low as or less than $160 \mathrm{~m}$. The areas with low PBL height are smaller in December 2007 and February 2013. In February 2013, the average PBL heights are much larger than those in the other three periods. The increases in the contributions from NHB and BJTJ indicate more frequent north winds blowing the pollutants from the northern area to Shijiazhuang. A comparison of the estimations for December 2007 and January 2013 shows that even for the most polluted months, a large fraction of $\mathrm{PM}_{2.5}$ in Shijiazhuang could originate from quite different regions (i.e., SX vs. NHB), which may mainly be due to the differences in meteorological conditions between the 2 months. The changes in the emissions between the year 2007 and 2013, which may result in some changes in atmospheric chemistry, could be another reason. It reveals the necessity of long-term modeling and analysis for the possibility of occurrence of severe haze under various meteorological conditions in future research, which should be taken into account in future policymaking on regional 

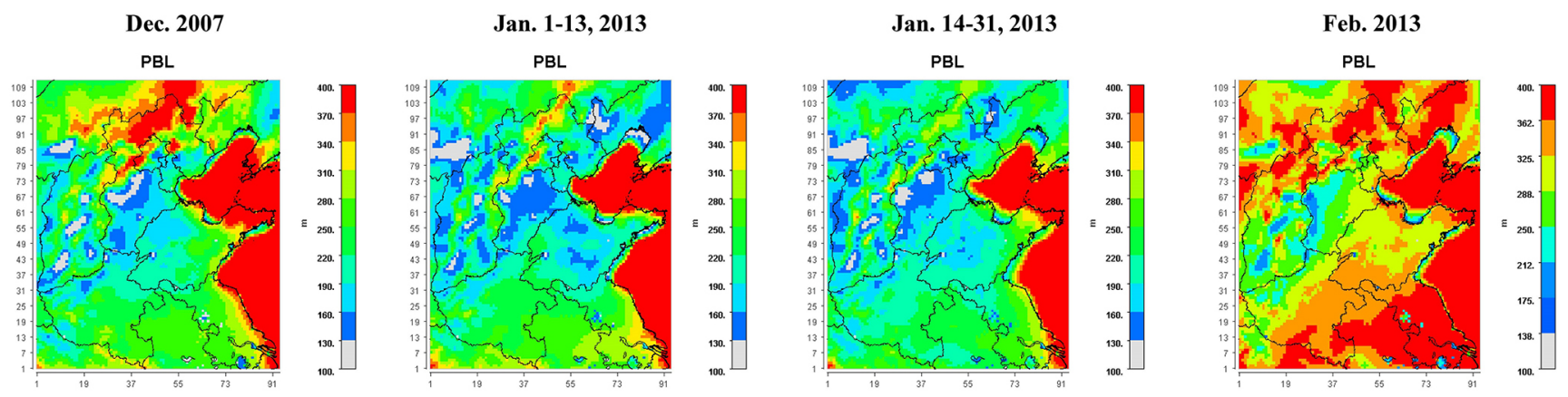

Fig. 8. Spatial distributions of simulated PBL height (m) in Domain 2 in December 2007, and 1-13 and 14-31 January, and February, 2013.

Table 5a. The average source contributions (\%) to the $\mathrm{PM}_{2.5}$ concentrations in Shijiazhuang, Xingtai, and Handan by source regions:

\begin{tabular}{lrrrr|rrrr|rrrr}
\hline Regions & \multicolumn{3}{c}{ Shijiazhuang } & \multicolumn{4}{c|}{ Xingtai } & \multicolumn{4}{c}{ Handan } \\
\hline & Dec & Jan & Jan & Feb & Dec & Jan & Jan & Feb & Dec & Jan & Jan & Feb \\
& 2007 & $\begin{array}{r}1-13, \\
14-31,\end{array}$ & 2013 & 2007 & $1-13$, & $14-31$, & 2013 & 2007 & $1-13$, & $14-31$, & 2013 \\
Periods & & 2013 & 2013 & & & 2013 & 2013 & & & 2013 & 2013 \\
\hline SHB & 65.1 & 75.8 & 67.2 & 66.4 & 64.0 & 77.1 & 65.9 & 63.9 & 64.2 & 73.1 & 65.2 & 63.0 \\
NHB & 7.2 & 9.0 & 17.8 & 15.0 & 5.5 & 4.4 & 13.0 & 10.1 & 5.0 & 3.9 & 10.3 & 7.9 \\
BJTJ & 0.9 & 0.9 & 3.4 & 3.2 & 1.1 & 1.3 & 2.9 & 3.2 & 1.0 & 1.1 & 2.4 & 2.8 \\
SX & 14.1 & 7.2 & 3.2 & 3.8 & 10.9 & 6.7 & 3.6 & 3.6 & 9.0 & 5.4 & 3.2 & 2.9 \\
SD & 1.5 & 1.1 & 1.7 & 3.8 & 3.5 & 1.3 & 3.4 & 5.8 & 4.4 & 1.8 & 3.8 & 6.2 \\
HN & 1.0 & 1.2 & 1.5 & 1.9 & 3.5 & 5.4 & 5.7 & 7.6 & 5.4 & 10.5 & 9.5 & 10.9 \\
\hline
\end{tabular}

emission control strategies to effectively control the severe haze in Shijiazhuang.

Figure 9 presents the contribution ranges from each region to the $\mathrm{PM}_{2.5}$ concentrations in Shijiazhuang. The contributions from the SHB, NHB, and SX have larger variations than those from other regions. For example, the highest local contributions can reach nearly $95 \%$ and the lowest can be less than $20 \%$. As for the NHB, the contributions fall into the range of $0-60 \%$, and the median values are between $7 \%$ and $30 \%$ for 14-31 January. The contributions from BJTJ, $\mathrm{SD}$, and $\mathrm{HN}$ are concentrated in smaller ranges, and might be considered as minor sources of the transboundary $\mathrm{PM}_{2.5}$ in Shijiazhuang.

It should be noted that the several factors resulting in underpredictions in $\mathrm{PM}_{2.5}$ concentrations may introduce uncertainties in the source apportionment results, for instance, the positive bias of wind prediction and lack of dust emissions will result in underestimations of the local source contribution, the lack of heterogeneous chemistry may lead to underestimation of some sources emitting more gas phase precursors, and uncertainties in spatial distributions of emissions could result in either negative or positive bias of local or regional contributions.

\subsubsection{Xingtai}

As shown in Table 5a, the source contribution in Xingtai is similar to that of Shijiazhuang, except for noticeable increases in the contributions from HN and SD. This is expected because Xingtai is closer to the two provinces than Shijiazhuang. The local sources contribute $77.1 \%$ and $65.9 \%$ for the period 1-13 and 14-31 January, respectively, which are higher than $64.0 \%$ in December 2007 and $63.9 \%$ in February 2013. The second largest contributor also changes from SX in December 2007 and 1-13 January to NHB for the period 14-31 January and February 2013, with the contributions from NHB of $13.0 \%$ and $10.1 \%$ for 14 31 January and February. Unlike Shijiazhuang where SX is the third largest contributor, $\mathrm{HN}$ is the third largest contributing region to $\mathrm{PM}_{2.5}$ in Xingtai, with $5.7 \%$ for January $14-31$, and $7.6 \%$ for February 2013. The average contributions from $\mathrm{SX}, \mathrm{SD}$, and BJTJ are respectively $3.6 \%, 3.4 \%$, and $2.9 \%$ for $1-13$ January, $3.6 \%, 3.4 \%$, and $2.9 \%$ for $14-31$ January, and $3.6 \%, 5.8 \%$, and $3.2 \%$ for February. The total regional contributions are $19.1 \%$ for 1-13 January, $28.6 \%$ for $14-31$ January, and $30.3 \%$ for February, which are slightly lower than $19.4 \%$ for $1-13$ January, and slightly higher than $27.5 \%$ and $27.8 \%$ for 14-31 January and February in Shijiazhuang. The total sources outside Hebei contribute $14.5 \%, 15.7 \%$, $20.3 \%$, and $19.0 \%$ for $1-13$ and $14-31$ January, February 2013, and December 2007, respectively. 
Table 5b. The average source contributions (\%) to the $\mathrm{PM}_{2.5}$ concentrations in Shijiazhuang, Xingtai, and Handan by source regions and sectors (for the period 14 January-28 February):

\begin{tabular}{lrrrrr|rrrrr|rrrrr}
\hline Regions & \multicolumn{5}{c|}{ Shijiazhuang } & \multicolumn{5}{|c}{ Xingtai } & \multicolumn{5}{c}{ Handan } \\
\hline Sectors & PO & IN & DO & TR & AG & PO & IN & DO & TR & AG & PO & IN & DO & TR & AG \\
\hline SHB & 0.6 & 29.7 & 24.6 & 4.4 & 9.4 & 0.5 & 27.3 & 27.6 & 1.8 & 9.9 & 0.6 & 28.8 & 25.1 & 3.0 & 8.8 \\
NHB & 0.0 & 3.3 & 8.0 & 0.0 & 2.7 & 0.0 & 2.2 & 5.1 & 0.0 & 2.2 & -0.1 & 1.7 & 4.1 & 0.0 & 1.8 \\
BJTJ & 0.0 & 0.9 & 1.5 & 0.0 & 0.2 & 0.0 & 1.0 & 1.5 & 0.0 & 0.2 & 0.0 & 0.8 & 1.2 & 0.0 & 0.2 \\
SX & 0.1 & 1.5 & 1.9 & 0.0 & 0.5 & 0.1 & 1.6 & 1.9 & 0.0 & 0.5 & 0.0 & 1.3 & 1.6 & 0.0 & 0.4 \\
SD & -0.1 & 0.4 & 1.3 & -0.1 & 0.9 & -0.1 & 0.7 & 2.0 & 0.0 & 1.3 & -0.1 & 0.7 & 2.3 & 0.0 & 1.4 \\
HN & -0.1 & 0.3 & 0.7 & -0.1 & 0.7 & -0.1 & 1.5 & 2.4 & 0.0 & 2.7 & -0.2 & 2.5 & 3.7 & 0.0 & 4.1 \\
Sum & 0.4 & 36.2 & 38.0 & 4.2 & 14.5 & 0.3 & 34.2 & 40.5 & 1.8 & 16.8 & 0.3 & 35.8 & 38.1 & 2.9 & 16.8 \\
\hline
\end{tabular}

$\mathrm{PO}$ - power plants. IN - industrial sources. DO - domestic sources. TR - transportation. AG - agricultural sources.

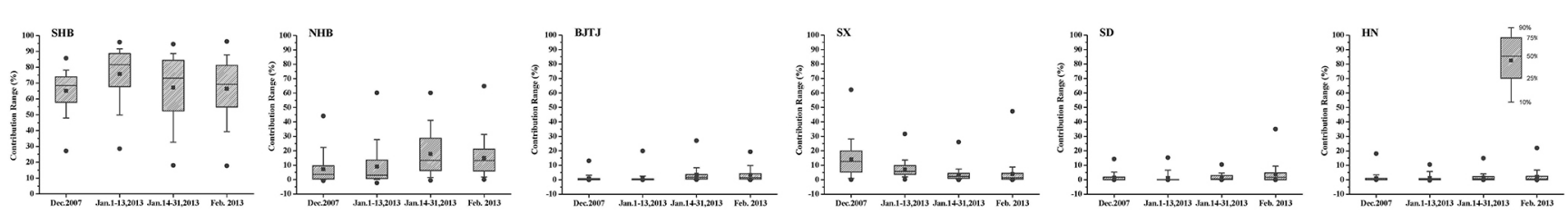

(a)
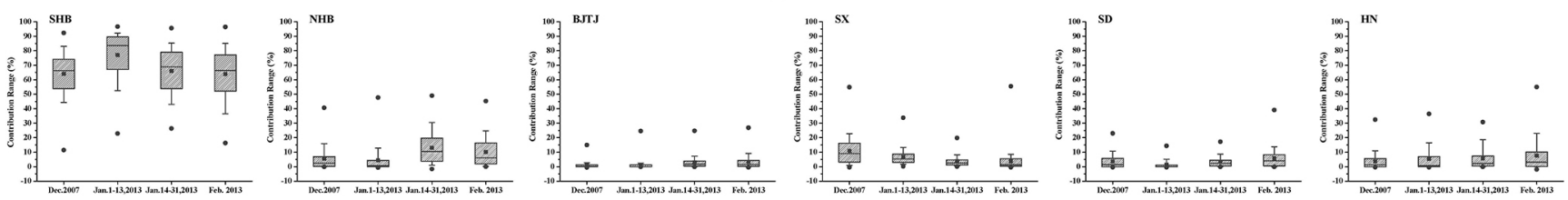

(b)
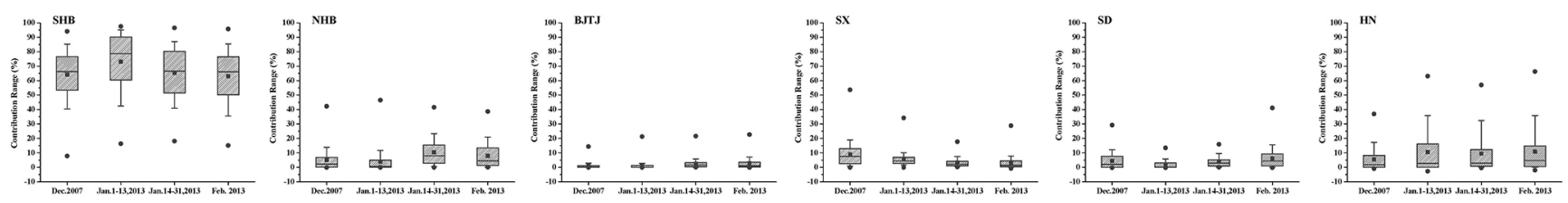

(c)

Fig. 9. The source contribution ranges by source regions to the $\mathrm{PM}_{2.5}$ concentrations in (a) Shijiazhuang, (b) Xingtai, and (c) Handan in December 2007, and 1-13 and 14-31 January, and February, 2013. Dot signs indicate the maximum and minimum, and square signs indicate the average value.

Figure 9 shows a significant increase in the contributions of $\mathrm{HN}$, namely, the maximum value could reach around $30 \%$ and the median values could fall into the range of $0.5 \%$ to $9 \%$ for the period 14-31 January 2013. Such contributions are sizeable and should not be ignored in the development of air pollution control strategies in Xingtai. Compared to Shijiazhuang, the contributions from NHB significantly decrease, but are not negligible ( $\sim 10 \%$ on average) and should thus also be taken into account. Although the mean contributions from SX and $\mathrm{HN}$ are relatively small, their variations are notably larger than those for Shijiazhuang, indicating that those sources should not be neglected under some special conditions. The contributions from BJTJ are the smallest and mostly concentrated into a small range. It is considered to be a minor source to $\mathrm{PM}_{2.5}$ in Xingtai. In summary, the source apportionment in Xingtai might be more complicated than that of Shijiazhuang because of its special location, smaller city area, and more complex emission environment outside the city.

\subsubsection{Handan}

Handan is located at the southern edge of Hebei Province, in the intersection area of Hebei, Shanxi, Henan, and Shandong. It is expected that the contributions from SD and HN are obviously larger than those for Shijiazhuang and Xingtai. As shown in Table $5,73.1 \%$ and $65.2 \%$ of $\mathrm{PM}_{2.5}$ originate from the local sources in 1-13 and 14-31 January, respectively, which are higher than $64.2 \%$ in December 2007 and 
$63.0 \%$ in February 2013. The contributions of NHB and HN to $\mathrm{PM}_{2.5}$ concentrations are $10.3 \%$ and $9.5 \%$, respectively, in 14-31 January, which are nearly two times their contributions in December 2007. This change may be attributed to the different meteorological conditions between the two months. In December 2007, more frequent eastern and western winds appeared over this area that increased the contributions of SX and SD but decreased those from NHB and HN (L. T. Wang et al., 2012). SD, SX, and BJTJ contribute to a total of $8.3 \%$ of the $\mathrm{PM}_{2.5}$ concentrations in 1-13 January, $9.4 \%$ in 14-31 January, and $11.9 \%$ in February, which are lower than $14.4 \%$ in December 2007. During the two periods of 1-13 and 14-31 January, a total of $22.7 \%$ and $29.2 \%$ of $\mathrm{PM}_{2.5}$ in Handan came from the regional sources, respectively, and $18.8 \%$ and $18.9 \%$ came from the sources outside Hebei Province, respectively. The regional contributions (i.e., total sources outside SHB) are $30.7 \%$ and $24.8 \%$ in February 2013 and December 2007, in particular, the contributions of the sources outside Hebei account for most of the regional contributions (i.e., $22.8 \%$ and $19.8 \%$, respectively) indicating that the sources from northern Hebei play a relatively small role in high $\mathrm{PM}_{2.5}$ concentrations in Handan. Therefore, regional joint prevention and control of air pollution are extremely necessary to improve air quality in Handan.

Figure 9 shows an increased importance of the contributions from $\mathrm{HN}$ and SD to air quality in Handan. Emissions from $\mathrm{HN}$ are of the same importance to those of NHB, in other words, the $75 \%$ percentiles are above $15 \%$ for $1-13$ January, $12 \%$ for $14-31$ January, and $15 \%$ for February. The maximum source contributions are as high as $64 \%, 56 \%$, and $65 \%$ for the three periods, respectively. Although the average contributions from SX and SD are not significant (2.9\% to $6.2 \%)$, the large variations indicate their importance to air quality in Handan under certain atmospheric conditions (e.g., when slow or calm winds in the east-west direction dominated). BJTJ remains as a minor contributor to Handan, which is similar to the cases in Shijiazhuang and Xingtai.

\subsubsection{Inter-influences of the three cities}

Figure 10 shows the source contributions of three cities, Shijiazhuang, Xingtai, and Handan to the $\mathrm{PM}_{2.5}$ concentrations in each city for the period 1-13 and 14-31 January, and February, to understand of their influences on each other. The source contributions of Xingtai and Handan to Shijiazhuang are $2.7 \%$ and $1.5 \%$, respectively, on the whole period average. The maximum contributions are about $20 \%$ for Xingtai, and $30 \%$ for Handan. Overall, $63.8 \%$ of $\mathrm{PM}_{2.5}$ in Shijiazhuang comes from the emissions within this city. As to each period, the contributions of Shijiazhuang's own sources are $71.8 \%$ for $1-13$ January, $64.0 \%$ for $14-31$ January, and $59.9 \%$ for February to Shijiazhuang.

The situations for Xingtai and Handan are quite different from that for Shijiazhuang. The source contributions from sources from Xingtai or Handan are obviously lower than those in Shijiazhuang. On average $46.0 \%$ of $\mathrm{PM}_{2.5}$ in Xingtai comes from the emissions within the city. The source contributions from Shijiazhuang and Handan are $9.0 \%$ and $10.4 \%$, respectively. The maximum contribution could reach around $50 \%$, as shown in Fig. 10b. In Handan, the contributions of its own sources are $49.4 \%$ on the whole period average, and Shijiazhuang and Xingtai contribute $4.7 \%$ and $9.9 \%$ on average, respectively. The highest contributions from Shijiazhuang and Xingtai could reach $40 \%$ and $50 \%$, respectively. The deference between Shijiazhuang and the other two cities may be attributed to their locations (e.g., Shijiazhuang is in the north of the three cities and the northern wind was more frequent in this 2013 case), different emission densities, and different areas (e.g., Shijiazhuang is the largest city of the three and has the highest emission densities). It implies the necessity of joint pollution controls of the three cities.

\subsection{Contributions by source regions and sectors}

\subsubsection{Shijiazhuang}

The average contributions by region and sector to the $\mathrm{PM}_{2.5}$ concentrations in Shijiazhuang during the period 14 January to 28 February are presented in Table $5 \mathrm{~b}$. The industrial and domestic emissions are the top two major local sources, with the concentration contributions of $29.7 \%$ and $24.6 \%$, respectively. Agricultural emissions, the major source of $\mathrm{NH}_{3}$, are the third largest contributor to $\mathrm{PM}_{2.5}$ in Shijiazhuang. This is expected because ammonium $\left(\mathrm{NH}_{4}^{+}\right)$transformed from $\mathrm{NH}_{3}$ is one of the most important compositions in atmospheric secondary inorganic aerosols. Transportation and power plants in local regions contribute $4.4 \%$ and $0.6 \%$ of the $\mathrm{PM}_{2.5}$ concentrations, respectively. As for the other regions, industrial and domestic sources in the NHB, BJTJ, and SX are also major contributors, contributing a total of $11.3 \%$, $2.4 \%$, and $3.4 \%$, respectively, of the $\mathrm{PM}_{2.5}$ concentrations in Shijiazhuang. Overall, $2.7 \%, 0.2 \%$, and $0.5 \%$ of $\mathrm{PM}_{2.5}$ originate from the agricultural sources in NHB, BJTJ, and SX, respectively. Transportation and power plants in those regions are minor sources to $\mathrm{PM}_{2.5}$ in Shijiazhuang, with nearly zero contributions. The agricultural sources from SD and $\mathrm{HN}$ become the second most important contributor (after the domestic sources), with the contributions of $0.9 \%$ and $0.7 \%$ to $\mathrm{PM}_{2.5}$ in Shijiazhuang. SD and $\mathrm{HN}$ are both among the large agricultural provinces in China, and SD ranks the first among all provinces in terms of agricultural GDP. Industrial emissions in the two provinces only contribute $0.4 \%$ and $0.3 \%$ in the $\mathrm{PM}_{2.5}$ concentration, respectively. Transportation and power plants are also minor sources. The total contributions from each sector, roughly estimated by adding the values from each region, are $0.4 \%$ from power plants, $36.2 \%$ from industrial, $38.0 \%$ from domestic, $4.2 \%$ from transportation, and $14.5 \%$ from agriculture. 

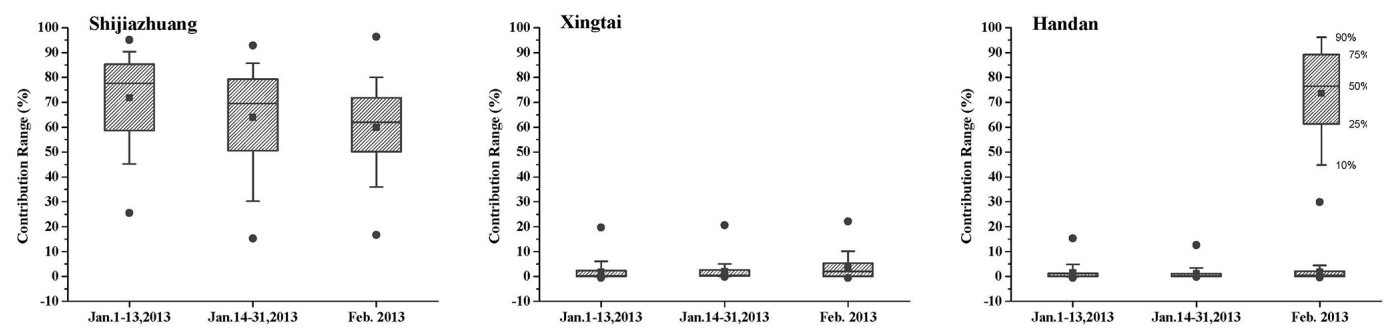

(a)
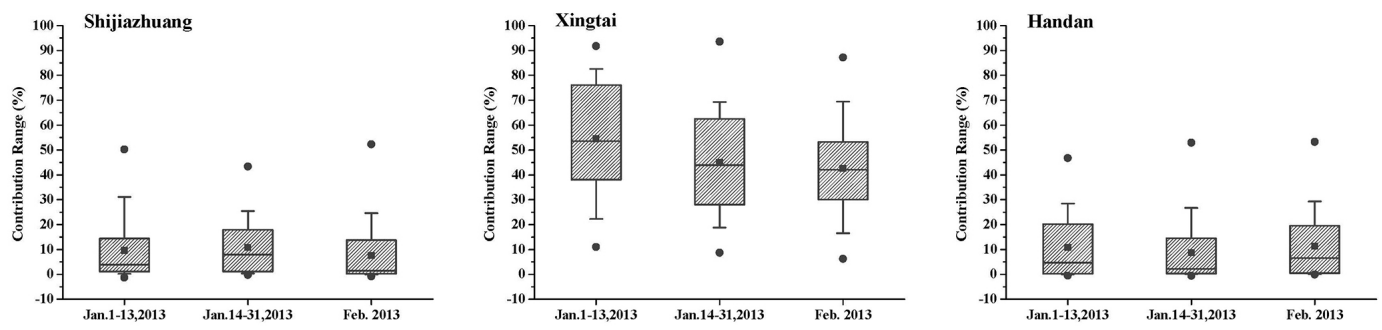

(b)
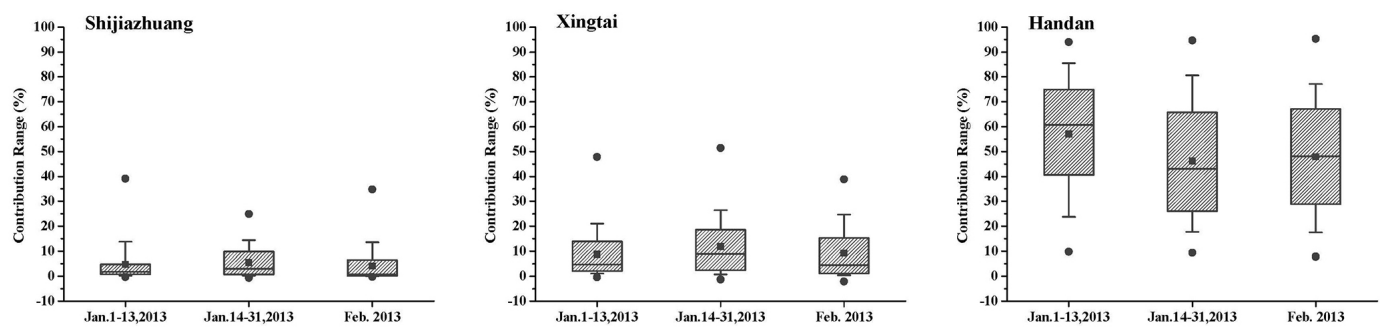

(c)

Fig. 10. The source contribution ranges by the three cities of Shijiazhuang, Xingtai, and Handan to (a) Shijiazhuang, (b) Xingtai, and (c) Handan in 1-13 and 14-31 January, and February, 2013. Dot signs indicate the maximum and minimum, and square signs indicate the average value.

The contribution ranges are plotted in Fig. 11a for 14-31 January and February separately, for each sector in each region. Despite the importance of the three sources, industrial, domestic, and agriculture, as discussed above, the contributions of industrial manufacturers slightly increase in SHB, BJTJ, and SD areas in February compared to January; however, the change in domestic sources in SHB and NHB are the opposite. The three major sectors in the local region should not be neglected in future controls of air pollution in Shijiazhuang, and also in NHB, BJTJ, and SX when regional joint controls are considered in policymaking.

\subsubsection{Xingtai}

As shown in Table $5 b$, the relative importance of the sectors in each region to the $\mathrm{PM}_{2.5}$ concentrations in Xingtai is similar to Shijiazhuang. Industrial and domestic sources are the two most important sources in the local region, which contribute $27.3 \%$ and $27.6 \%$, respectively, of the $\mathrm{PM}_{2.5}$ con- centrations. Those two sectors from NHB, BJTJ, and SX are also small but not negligible, with the contributions of $2.2 \%$, $1.0 \%$, and $1.6 \%$ for the industrial sector and $5.1 \%, 1.5 \%$, and $1.9 \%$ for the domestic sector, respectively. A difference between the contributions in Xingtai and Shijiazhuang lies in the notable increase in agricultural contributions from $\mathrm{SD}$ and $\mathrm{HN}$, i.e., $1.3 \%$ and $2.7 \%$ of $\mathrm{PM}_{2.5}$ are originated from agricultural sources in the two provinces, respectively. It should be noted that the contributions from agricultural sources of $\mathrm{HN}$ even exceed its domestic sources (2.4\%). It may imply that the $\mathrm{NH}_{4}^{+}$in the secondary aerosols in Xingtai originates more from regional sources than in Shijiazhuang. The total contributions of each sector are $0.3 \%$ from power plants, $34.2 \%$ from industrial, $40.5 \%$ from domestic, $1.8 \%$ from transportation, and $16.8 \%$ from agriculture.

As shown in Fig. 11b, the most significant difference between the source contributions in Shijiazhuang and Xingtai is the obvious increases in the contributions of the sources 


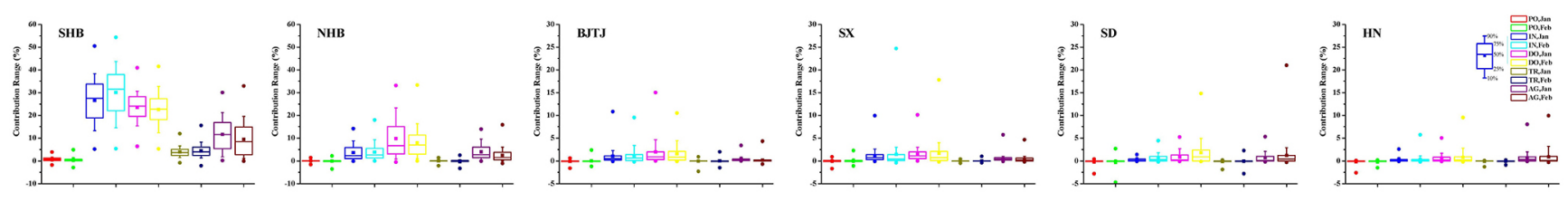

(a)
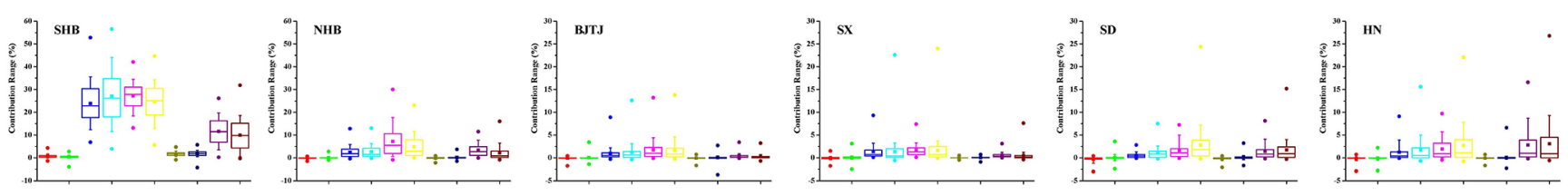

(b)
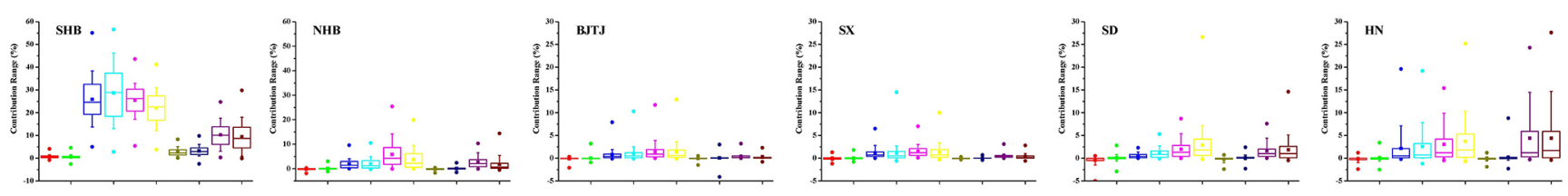

(c)

Fig. 11. Source contributions by region and sector to the $\mathrm{PM}_{2.5}$ concentrations in (a) Shijiazhuang, (b) Xingtai, and (c) Handan from 14 January to February 2013. Dot signs indicate the maximum and minimum, and square signs indicate the average value.

from the two provinces, SD and HN, especially for the three key sectors (industrial, domestic, and agricultural sectors). It indicates that despite the controls in the industrial and domestic emissions in those provinces (which are usually emphasized in previous control strategies), controls of the agricultural emissions in the neighborhood provinces should be further considered to more effectively mitigate PM pollution in Xingtai.

\subsubsection{Handan}

The two major local sources from SHB, industrial and domestic, contribute $28.8 \%$ and $25.1 \%$, respectively, of the total $\mathrm{PM}_{2.5}$ concentrations in Handan, followed by $8.8 \%$ from agricultural sources. Given the special location of Handan, the contributions from SD and HN further increase compared to Shijiazhuang and Xingtai. The agricultural emissions of SD and $\mathrm{HN}$ contribute $1.4 \%$ and $4.1 \%$ in $\mathrm{PM}_{2.5}$, respectively, which are slightly higher than those from domestic sources $(2.3 \%$ and $3.7 \%)$ and noticeably higher than those of industrial sources $(0.7 \%$ and $2.5 \%)$. The total contributions of each sector are roughly estimated to be $0.3 \%$ for power plants, $35.8 \%$ for industrial, $38.1 \%$ for domestic, $2.9 \%$ for transportation, and $16.8 \%$ for agriculture.

Compared with Shijiazhuang and Xingtai, a significant increase in the contributions of all the sectors in $\mathrm{HN}$ is found for Handan, as shown in Fig. 11c, especially for agriculture, domestic, and industrial. The industrial, domestic, and agricultural sources in $\mathrm{HN}$ contribute $2.5 \%, 3.7 \%$, and $4.1 \%$, respectively, of the $\mathrm{PM}_{2.5}$ concentrations in Handan. The
SD's contributions are slightly higher in Handan than those in Xingtai. As discussed above for Xingtai, more effective PM controls in Handan should include not only the major sources in local regions, but also domestic, agricultural, and industrial emissions from SD and $\mathrm{HN}$.

\section{Conclusions}

In this study, the haze frequencies are first analyzed for the seven representative cities in northern China, i.e., Shijiazhuang, Xingtai, Beijing, Tianjin, Taiyuan, Zhengzhou, and Jinan for the years 2001 to February 2013. January 2013 and December 2007 are identified as the top two most polluted months since 2001 in terms of the haze frequencies. However, more frequent foggy days and much lower visibilities indicate January 2013 to be the most polluted month. The MM5-CMAQ air quality modeling system is then applied to simulate the extremely severe haze events that occurred in eastern China in January and February 2013, using the MEIC inventory. The model performance is evaluated against the meteorological observations throughout off of China and against air quality observations at more than 400 national sites in the 74 major environmental protection cities. The model shows an overall acceptable performance and the MEIC inventory are proven to give a good estimation on total emissions of cities. The relative humidity at $2 \mathrm{~m}$ and wind speed at $10 \mathrm{~m}$ are well reproduced by the model, while temperature at $2 \mathrm{~m}$ and daily precipitation are underpredicted. $\mathrm{PM}_{2.5}$ and $\mathrm{PM}_{10}$ concentrations are underpredicted during 
extremely polluted episodes due to the biases in the meteorological predictions, the uncertainties in the spatial allocation of emissions, the lack of dust emissions and the weakness of the model in the treatment of the heterogeneous formation of secondary aerosols on the surface of atmospheric particles.

The contributions by source regions and by source sectors in each region, to the $\mathrm{PM}_{2.5}$ concentrations in Shijiazhuang, Xingtai, and Handan (which are listed as the top three most polluted cities in China), are analyzed using CMAQ with the Brute Force method and the results are compared with those for December 2007. Even in the top two most polluted months (i.e., January 2013 and December 2007) a large fraction of $\mathrm{PM}_{2.5}$ in those cities may originate from quite different regional sources. In January 2013, more $\mathrm{PM}_{2.5}$ in the three cities came from the northern area, such as NHB and BJTJ. The contributions from SX significantly decrease and those from HN obviously increase in January 2013 compared with those in February 2007. In general, the regional sources contribute $27.5 \%$ (Shijiazhuang) to $28.6 \%$ (Handan) of the $\mathrm{PM}_{2.5}$ concentrations in the three cities in January 2013. Within the three cities, only $4.2 \%$ of $\mathrm{PM}_{2.5}$ in Shijiazhuang comes from Xingtai and Handan, but $19.5 \%$ of $\mathrm{PM}_{2.5}$ in Xingtai and $14.6 \%$ in Handan come from the other two cities.

Industrial and domestic emissions from the local sources contribute $\sim 28 \%$ and $27 \%$, respectively, of the $\mathrm{PM}_{2.5}$ concentrations in the three cities, followed by the local agricultural sources. The domestic and industrial sources in the NHB, BJTJ, and SX are the two most important contributors to PM concentrations in Shijiazhuang, Xingtai, and Handan. However, the top two largest contributors in SD and HN to $\mathrm{PM}_{2.5}$ concentrations in Xingtai and Handan are domestic and agricultural emissions from SD and HN. The special locations, huge amounts of pollutants emissions, and highly complex emission environment, pose a significant challenge to mitigating air pollution in southern Hebei to meet the national standards for $\mathrm{PM}_{2.5}$ and $\mathrm{PM}_{10}$ concentrations. Air pollution control in the three major cities in southern Hebei indicates potential problems in the existing framework and mechanism of regional joint policymaking (e.g., lack of coordination among provinces for regional pollution control efforts), control strategies (e.g., ignoring agricultural $\mathrm{NH}_{3}$ emissions control), and effective enforcement of control measures (e.g., lack of a mandatory implementation action system that is similar to the State Implementation Plan (SIP) in the US).

This study has several limitations. First, uncertainties (e.g., uncertainties in the spatial allocation) and limitations in emissions (e.g., the lack of an online dust emission module) may be propagated to the model predictions of $\mathrm{PM}_{2.5}$ and $\mathrm{PM}_{10}$ concentrations. Second, the observational data of $\mathrm{PM}_{2.5}$ compositions can provide insights into the causes for underpredictions during the extremely polluted periods over southern Hebei. Such data, however, are unavailable for model evaluation in this work. Third, although BFM is ca- pable of quantifying the direct and indirect effects due to interactions among PM and PM precursors, it cannot attribute $100 \%$ of atmospheric pollutants concentrations to source emissions as does a true source apportionment method. Better understanding can be expected in the future by intercomparing source contributions using both source sensitivity and source apportionment methods. Nevertheless, this study provides valuable scientific insights into the extremely severe haze that occurred over those cities and thus lays a foundation to the future policymaking, not only within the Hebei Province but also for the entire region of China, where severe pollution episodes frequently occur.

Acknowledgements. This study was co-sponsored by the National Natural Science Foundation of China (No. 41105105), the Natural Science Foundation of Hebei Province (No. D2011402019), the State Environmental Protection Key Laboratory of Sources and Control of Air Pollution Complex (No. SCAPC201307), the Excellent Young Scientist Foundation of Hebei Education Department (No. YQ2013031), the Program for the Outstanding Young Scholars of Hebei Province, and the China Scholarship Council at HEBEU, China and the US DOE climate modeling programs (DE-SC0006695) at NCSU, USA.

Edited by: G. Carmichael

\section{References}

Binkowski, F. S. and Shankar, U.: The Regional Particulate Model. 1. Model Description and Preliminary Results, J. Geophys. Res., 100, 26191-26209, 1995.

Blackadar, A. K.: Modeling the Nocturnal Boundary Layer, in: Proceedings of the Third Symposium on Atmospheric Turbulence, Diffusion and Air Quality, Amer. Meteor. Soc., Raleigh, NC, USA, 19-22 October 1976, 46-49, 1976.

Boylan, J. W.: PM Model Performance Goal and Criteria. Presented at the National Regional Planning Organizations Modeling Meeting, Denver, CO, USA, 9-10 June, 2005.

Burr, M. B. and Zhang, Y.: Source Apportionment of $\mathrm{PM}_{2.5}$ over the Eastern U.S., Part I. Source Sensitivity Simulations using CMAQ with the Brute Force Method, Atmos. Pollut. Res., 2, 300-317, doi:10.5094/APR.2011.037, 2011a.

Burr, M. B. and Zhang, Y.: Source Apportionment of $\mathrm{PM}_{2.5}$ over the Eastern U.S. using CMAQ, Part II: Source Apportionment Simulations using CAMx/PSAT and Comparisons with CMAQ Source Sensitivity Simulations, Atmos. Pollut. Res., 2, 318-336, doi:10.5094/APR.2011.036, $2011 \mathrm{~b}$.

Carlton, A. G., Pinder, R. W., Bhave, P. V., and Pouliot, G. A.: To what extent can biogenic SOA be controlled?, Environ. Sci. Technol., 44, 3376-3380, 2010.

Carter, W. P. L.: A Detailed Mechanism for the Gas-Phase Atmospheric Reactions of Organic Compounds, Atmos. Environ., 24, 481-518, 1990.

Carter, W. P. L.: Implementation of the SAPRC-99 chemical mechanism into the Models-3 Framework, Report to the U.S. EPA, Statewide Air Pollution Research Center, University of California, Riverside, CA, 2000. 
Chang, J. S., Brost, R. A., Isaksen, I. S. A., Madronich, S., Middleton, P., Stockwell, W. R., and Walcek, C. J.: A ThreeDimensional Acid Deposition Model: Physical Concepts and Formulation, J. Geophys. Res., 92, 14681-14700, 1987.

Chen, D. S., Cheng, S. Y., Liu, L., Chen, T., and Guo, X. R.: An integrated MM5-CMAQ modeling approach for assessing transboundary $\mathrm{PM}_{10}$ contribution to the host city of 2008 Olympic summer games-Beijing, China, Atmos. Environ., 41, 1237-1250, 2007

Chen, D. S., Cheng, S. Y., Liu, L., Lei, T., Guo, X. R., and Zhao, X. Y.: Assessment of the Integrated ARPS-CMAQ Modeling System through Simulating $\mathrm{PM}_{10}$ Concentration in Beijing, China, Environ. Eng. Sci., 25, 191-206, 2008.

Cohan, D. S., Hakami, A., Hu, Y., and Russel, A. G.: Nonlinear response of ozone to emissions: source apportionment and sensitivity analysis, Environ. Sci. Technol., 39, 6739-6748, 2005.

Deardorff, J. W.: Efficient Prediction of Ground Surface Temperature and Moisture, with Inclusion of a Layer of Vegetation, J. Geophys. Res., 83, 1889-1903, 1978.

Dudhia, J. A.: Non-Hydrostatic Version of the Penn State/NCAR Mesoscale Model: Validation Tests and Simulation of an Atlantic Cyclone and Cold Front, Mon. Weather Rev., 121, 1493-1513, 1993.

Dunker, A. M., Morris, R. E., Pollack, A. K., Schleyer, C. H., and Yarwood, G.: Photochemical modeling of the impact of fuels and vehicles on urban ozone using auto oil program data, Environ. Sci. Technol., 30, 787-801, 1996.

Dunker, A. M., Yarwood, G., Ortmann, J. P., and Wilson, G. M.: The decoupled direct method for sensitivity analysis in a threedimensional air quality model implementation, accuracy and efficiency, Environ. Sci. Technol., 36, 2965-2976, 2002.

Fan, Y. Q., Li, E. J., and Fan, Z. L: Visibility trends in 11 cities of Hebei Province during 1950-2002, Chin. J. Atmos. Sci., 29, 526-535, 2005 (in Chinese).

Fu, J. S., Jang, C. J., Streets, D. G., Li, Z. P., Kwok, R., Park, P., and Han, Z. W.: MICS-Asia II: evaluating gaseous pollutants in East Asia using an advanced modeling system: Models-3/CMAQ System, Atmos. Environ., 42, 3571-3583. doi:10.1016/j.atmosenv.2007.07.058, 2008.

Fu, J. S, Streets, D. G., Jang, C. J., Hao, J. M., He, K. B., Wang, L. T., and Zhang, Q: Modeling Regional/Urban Ozone and Particulate Matter in Beijing, China, J. Air Waste Manage., 59, 37-44, 2009

Gao, Y. and Zhang, M. G.: Sensitivity analysis of surface ozone to emission controls in Beijing and its neighboring area during the 2008 Olympic Games, J. Environ. Sci.-China, 24, 50-61, 2012.

Glotfelty, T., Zhang, Y., Karamchandani, P., and Streets, D. G.: Will the role of intercontinental transport change in a changing climate?, Atmos. Chem. Phys. Discuss., 13, 26489-26527, doi:10.5194/acpd-13-26489-2013, 2013.

He, K. B.: Multi-resolution Emission Inventory for China (MEIC): model framework and 1990-2010 anthropogenic emissions, International Global Atmospheric Chemistry Conference, 17-21 September, Beijing, China, 2012.

Kain, J. S. and Fritsch, J. M.: Convective Parameterization for Mesoscale Models: the Kain-Fritsch Scheme, in: The representation of cumulus convection in numerical models, Emanuel, K. A., Raymond, D. J. (Eds), Amer. Meteor. Soc., 246 pp., Boston, MA, USA, 165-170, 1993.
Lei, Y., Zhang, Q., He, K. B., and Streets, D. G.: Primary anthropogenic aerosol emission trends for China, 1990-2005, Atmos. Chem. Phys., 11, 931-954, doi:10.5194/acp-11-931-2011, 2011a.

Lei, Y., Zhang, Q., Nielson, C. P., and He, K. B.: An inventory of primary air pollutants and $\mathrm{CO}_{2}$ emissions from cement production in China, 1990-2020, Atmos. Environ., 55, 147-154, 2011b.

Li, N., Fu, T. M., Cao, J. J., Lee, S. C., Huang, X. F., He, L. Y., Ho, K. F., Fu, J. S., and Lam, Y. F.: Sources of secondary organic aerosols in the Pearl River Delta region in fall: Contributions from the aqueous reactive uptake of dicarbonyls, Atmos. Environ., 76, 200-207, 2013.

Liu, X. H., Zhang, Y., Cheng, S. H., Xing, J., Zhang, Q., Streets, D. G., Jang, C. J., Wang, W. X., and Hao, J. M.: Understanding of regional air pollution over China using CMAQ, Part I. Performance evaluation and seasonal variation, Atmos. Environ., 44, 2415-2426, 2010a.

Liu, X. H., Zhang, Y., Xing, J., Zhang, Q., Wang, K., Streets, D. G., Jang, C. J., Wang, W. X., and Hao, J. M.: Understanding of regional air pollution over China using CMAQ, part II. Process analysis and sensitivity of ozone and particulate matter to precursor emissions, Atmos. Environ., 44, 3719-3727, 2010b.

Liu, X. H., Zhang, Y., Olsen, K. M., Wang, W. X., Do, B. A., and Bridgers, G. M.: Responses of future air quality to emission controls over North Carolina, Part I: Model evaluation for currentyear simulations, Atmos. Environ., 44, 2443-2456, 2010 c.

Lu, X. Y., Tang, J., Zhang, J., Yue, J., Song, G. K., and Hu, J. G.: Annual report on analysis of Beijing society-building, Social Science Academic Press, Beijing, China, 2013.

Marmur A., Unal. A., Mulholland J. A., and Russell A. G.: Optimization Based Source Apportionment of $\mathrm{PM}_{2.5}$ Incorporating Gas-to-Particle Ratios, Environ. Sci. Technol., 39, 3245-3255, 2005.

MEP: China National Ambient Air Quality Standards, GB30952012, MEP, Beijing, China, 2012.

MEP: 2012 report on the state of the evironment in China, MEP, Beijing, China, 2013.

Morris, R., Koo, B., McNally, D., McNally, D., Tesche, T. W., and Tonnesen, G: Application of Multiple Models to Simulation Fine Particulate in the Southeastern U.S. Presented at the National Regional Planning Organizations Modeling Meeting, Denver, CO, USA, 9-10 June, 2005.

Napelenok, S. L., Cohan, D. S., Hu, Y., and Ressell, A. G.: Decoupled direct 3D sensitivity analysis for particulate matter (DDM3D/PM), Atmos. Environ., 40, 6112-6121, 2006.

NBS: China Statistical Yearbook 2012. China Statistical Press, Beijing, China, 2012a.

NBS: China Energy Statistical Yearbook 2012. China Statistical Press, Beijing, China, 2012b.

NBS: China Statistical Yearbook 2013. China Statistical Press, Beijing, China, 2013.

Queen, A., Zhang, Y., Gilliam, R., and Pleim, J.: Examining the sensitivity of MM5eAMAQ predictions to explicit, microphysics schemes, part I-database description, evaluation protocol and precipitation predictions, Atmos. Environ., 42, 3842-3855, 2008

Reisner, J., Rasmussen, R. J., and Bruintjes, R. T.: Explicit Forecasting of Supercooled Liquid Water in Winter Storms Using the MM5 Mesoscale Model, Q. J. Roy. Meteor. Soc., 124B, 10711107, 1998. 
SEPA (State Environmental Protection Agency): China National Ambient Air Quality Standards, GB3095-1996, SEPA, Beijing, China, 1996.

Streets, D. G., Fu, J. S., Jang, C. J., Hao, J. M., He, K. B., Tang, X. Y., Zhang, Y. H., Wang, Z. F., Li, Z. P., Zhang, Q., Wang, L. T., Wang, B. Y., and Yu, C.: Air quality during the 2008 Beijing Olympic Games, Atmos. Environ., 41, 480-492, 2007.

Tonnessen, G. and Wang, Z.: Development of a Tagged Species Source Apportionment Algorithm (TSSA) to Characterize 3Dimensional Transport and Transformation of Precursors and Secondary Pollutants, Final Report, University of California, Riverside, USA, 2007.

US EPA: Guidance on the Use of Models and Other Analyses for Demonstrating Attainment of Air Quality Goals for Ozone, $\mathrm{PM}_{2.5}$, and Regional Haze. Office of Air and Radiation/Office of Air Quality Planning and Standards, Research Triangle Park, NC, 2007.

US EPA: Peer Review of Source Apportionment Tools in CAMx and CMAQ. EP-D-07-102, Research Triangle Park, NC 27711, USA, 2009.

Uno, I., He, Y., Ohara, T., Yamaji, K., Kurokawa, J.-I., Katayama, M., Wang, Z., Noguchi, K., Hayashida, S., Richter, A., and Burrows, J. P.: Systematic analysis of interannual and seasonal variations of model-simulated tropospheric $\mathrm{NO}_{2}$ in Asia and comparison with GOME-satellite data, Atmos. Chem. Phys., 7, 16711681, doi:10.5194/acp-7-1671-2007, 2007.

Walcek, C. J. and Taylor, G. R.: A Theoretical Method for Computing Vertical Distributions of Acidity and Sulfate Production within Cumulus Clouds, J. Atmos. Sci., 43, 339-355, 1986.

Wang, C. M., Yang, Y. S., Li, Y. Z., and Fan, Y. Q.: Analysis on the Meteorological Condition and Formation Mechanism of Serious Pollution in South Hebei Province in January 2013, Research of Environmental Science, 26, 695-702, 2013 (in Chinese).

Wang, K., Zhang, Y., Jang, C. J., Phillips, S., and Wang, B. Y.: Modeling study of intercontinental air pollution transport over the trans-pacific region in 2001 using the community multiscale air quality (CMAQ) modeling system, J. Geophys. Res., 114, D04307, doi:10.1029/2008JD010807, 2009.

Wang, L. T., Hao, J. M., He, K. B., Wang, S. X., Li, J., Zhang, Q., Streets, D. G., Fu, J. S., Jang, C. J., Takekawa, H., and Chatani, S: A modeling study of coarse particulate matter pollution in Beijing: regional source contributions and control implications for the 2008 Summer Olympics, J. Air Waste Manage., 58, 10571069, doi:10.3155/1047-3289.58.8.1057, 2008.

Wang, L. T., Jang, C. J., Zhang, Y., Wang, K., Zhang, Q., Streets, D. G., Fu, J. S., Lei, Y., Schreifels, J., He, K. B., Hao, J. M., Lam, Y. F., Lin, J., Meskhidze, N., Voorhees, S., Evarts, D., and Phillips, S.: Assessment of air quality benefits from national air pollution control policies in China. Part II: Evaluation of air quality predictions and air quality benefits assessment, Atmos. Environ., 44, 3449-3457, 2010.

Wang, L. T., Xu, J., Yang, J., Zhao, X. J., Wei, W., Cheng, D. D., Pan, X. M., and Su, J.: Understanding haze pollution over the southern Hebei area of China using the CMAQ model, Atmos. Environ., 56, 69-79, 2012.

Wang, L. T., Yang, J., Zhang, P., Zhao, X. J., Wei, Z., Zhang, F. F., Su, J., and Meng, C. C.: A Review of Air Pollution and Control in Hebei Province, China, Open J. Air Pollut., 2013, 47-55, doi:10.4236/ojap.2013.23007, 2013.
Wang, S. W., Zhang, Q., Streets, D. G., He, K. B., Martin, R. V., Lamsal, L. N., Chen, D., Lei, Y., and Lu, Z.: Growth in $\mathrm{NO}_{\mathrm{x}}$ emissions from power plants in China: bottom-up estimates and satellite observations, Atmos. Chem. Phys., 12, 4429-4447, doi:10.5194/acp-12-4429-2012, 2012.

Wang, S. X., Xing, J., Jang, C., Zhu, Y., Fu, J. S., and Hao, J. M.: Impact assessment of ammonia emissions on inorganic aerosols in East China using response surface modeling technique, Environ. Sci. Technol., 45, 9293-9300, 2011.

Wang, Y. X., Zhang, Q., Q., Jiang, J. K., and Zhang, B.: PM 2.5 pollution over China: understanding the roles of chemistry and meteorology, presented at School of Engineering and Applied Science, Washington University of St. Louis, 2 May, 2013.

Wang, Z. S., Chien, C. J., and Tonnesen, G. S.: Development of a tagged species source apportionment algorithm to characterize three dimensional transport and transformation of precursors and secondary pollutants, J. Geophys. Res., 114, D21206, doi:10.1029/2008JD010846, 2009.

Wei, W. X.: Spatial-temporal characteristics of haze in Hebei Province, Meteor. Mon., 36, 76-81, 2010 (in Chinese).

Wei, W. X., Zhang, X., and Tian, G. Q.: Analysis of relation between haze distribution and terrain and wind speed in Hebei Province., J. Nat. Disasters, 19, 49—52, 2010 (in Chinese).

Wei, Z., Yang, J., Wang, L. T., Wei, W., Zhang, F. F., Su, J., Zhang, P., and Zhao, X. J.: Characteristics of the severe haze episode in Handan city in January, 2013, Acta Scientiae Circumstantiae, accepted, 2013 (in Chinese).

Wu, S. Y., Krishnan, S., Zhang, Y., and Aneja, V.: Modeling atmospheric transport and fate of ammonia in North Carolina, Part I. Evaluation of meteorological and chemical predictions, Atmos. Environ., 42, 3419-3436, 2008.

Xing, J., Zhang, Y., Wang, S. X., Liu, X. H., Cheng, S. H., Zhang, Q., Chen, Y. S., Streets, D., G., Jang, C. J., Hao, J. M., and Wang, W. X.: Modeling study on the air quality impacts from emission reductions and a typical meteorological conditions during the 2008 Beijing Olympics, Atmos. Environ., 45, 1786-1798, 2011.

Yang, Y. J., Wilkinson, J. G., and Russell, A. G.: Fast, direct sensitivity analysis of multidimensional photochemical models, Environ. Sci. Technol., 31, 2859-2868, 1997.

Zhang, D. L. and Anthes, R. A.: A high-resolution model of the planetary boundary layer- sensitive tests and comparisons with SESAME-79 data, J. Appl. Meteorol., 21, 1594-1609, 1982.

Zhang, M., Uno, I., Zhang, R. J., Han, Z. W., Wang, Z. F., and Pu, Y. F.: Evaluation of the models-3 community multi-scale air quality (CMAQ) modeling system with observations obtained during the TRACE-P experiment: comparison of ozone and its related species, Atmos. Environ., 40, 4874-4882, 2006.

Zhang, Q., Streets, D. G., He, K. B., Wang, Y. X., Ritcher, A., Burrows, J. P., Uno, I., Jang, C. J., Chen, D., Yao, Z. L., and Lei, Y.: $\mathrm{NO}_{\mathrm{X}}$ emission trends for China, 1995-2004: The view from the ground and the view from space, J. of Geophys. Res., 112, D22306, doi:10.1029/2007JD008684, 2007.

Zhang, Q., Streets, D. G., Carmichael, G. R., He, K. B., Huo, H., Kannari, A., Klimont, Z., Park, I. S., Reddy, S., Fu, J. S., Chen, D., Duan, L., Lei, Y., Wang, L. T., and Yao, Z. L.: Asian emissions in 2006 for the NASA INTEX-B mission, Atmos. Chem. Phys., 9, 5131-5153, doi:10.5194/acp-9-5131-2009, 2009. 
Zhang, S. M.: Relationship between the Visibility Degradation and Particle Pollution in Shijiazhuang. Hebei Normal University, Shijiazhuang, Hebei, China, 2009 (in Chinese).

Zhang, Y. and Carmichael, G. R: The Role of Mineral Aerosol in Tropospheric Chemistry in East Asia-a Model Study, J. Appl. Meteorol., 38, 353-366, 1999.

Zhang, Y. and Wu, S. Y.: Fine Scale Modeling of Agricultural Air Quality over the Southeastern United States using Two Air Quality Models, Part II. Sensitivity Studies and Policy Implications, Aerosol Air Qual. Res., 13, 1475-1491, 2013.

Zhang, Y., Vijayaraghavan, K., and Seigneur, C.: Evaluation of Three Probing Techniques in a Three-Dimensional Air Quality Model, J. Geophys. Res., 110, D02305, doi:10.1029/2004JD005248, 2005.

Zhang, Y., Liu, P., Pun, B., and Seigneur, C.: A comprehensive performance evaluation of MM5-CMAQ for the Summer 1999 Southern Oxidants Study episode-Part I: Evaluation protocols, databases, and meteorological predictions, Atmos. Environ., 40, 4825-4838, 2006.
Zhang Y., Cheng, S. H., Chen, Y. S., and Wang, W. X.: Application of MM5 in China: Model evaluation, seasonal variations, and sensitivity to horizontal grid resolutions, Atmos. Environ., 45, 3454-3465, 2011.

Zhou, Y., Fu, J. S., Zhuang, G. S., and Levy, J. I.: Risk-Based Prioritization among Air Pollution Control Strategies in the Yangtze River Delta, China, Environ. Health Persp., 118, 1204-1210, 2010.

Zhou, Y., Cheng, S. Y., Liu, L., and Chen, D. S.: A Coupled MM5CMAQ Modeling System for Assessing Effects of Restriction Measures on $\mathrm{PM}_{10}$ Pollution in Olympic City of Beijing, China, J. Environ. Informatics, 19, 120-127, 2012. 